Portland State University

PDXScholar

Summer 8-14-2013

\title{
From College to Career: Understanding First Generation and Traditional Community College Transfer Students' Major and Career Choices
}

Jeff Scott Shelton

Portland State University

Follow this and additional works at: https://pdxscholar.library.pdx.edu/open_access_etds

Part of the Educational Sociology Commons, and the Social Psychology and Interaction Commons Let us know how access to this document benefits you.

Recommended Citation

Shelton, Jeff Scott, "From College to Career: Understanding First Generation and Traditional Community College Transfer Students' Major and Career Choices" (2013). Dissertations and Theses. Paper 1408. https://doi.org/10.15760/etd.1408

This Thesis is brought to you for free and open access. It has been accepted for inclusion in Dissertations and Theses by an authorized administrator of PDXScholar. Please contact us if we can make this document more accessible: pdxscholar@pdx.edu. 
From College to Career: Understanding First Generation and Traditional Community

College Transfer Students' Major and Career Choices

\author{
by
}

Jeff Scott Shelton

A thesis submitted in partial fulfillment of the requirements for the degree of

Master of Science

in

Sociology

Thesis Committee:

Peter Collier, Chair

David Morgan

Joan Jagodnik

Portland State University

2013 
(C) 2013 Jeff Scott Shelton 


\begin{abstract}
While the connection between major choice and career goals seems logically obvious, research exploring this process is limited, particularly concerning how socio-economic class, based on parents' educational levels, influences the choice process. An important initial step in understanding this larger process is to explore how SES-based differences affect the process of choosing a major, a career goal and the way in which students link their major to a possible career.

This study utilizes a comparative interview design to explore the lived experiences regarding major and career aspirations of first generation and traditional college seniors who have transferred from a community college to Portland State University. This study considers a first generation student to be any student that does not have a parent that has graduated from a four-year university in the United States. A traditional student is any student that has one or more parents who have earned at least a four-year degree in the U.S. Using a conceptual framework based on Pierre Bourdieu's work on social reproduction, this qualitative interview study examines how social and cultural capital as well as habitus influences first generation and traditional community college transfer students' choice of career, major and the link these students make between the two.
\end{abstract}

This research found that the majority of students, both first generation and traditional community college transfer students, gained domain specific information that helped them with their major and or career goals from mentors such as, professors and academic advisers. However, Traditional students received "life advice" and 
encouragement from family members and employers that helped them to stay on track and gain inside information regarding their career choices. Traditional students used their past and current work history to assist them in strengthening their chances at realizing their career goals. Many traditional students planned to use the degrees they earned at college to advance within fields they already were working in. In comparison, it was only after they started college and settled on specific majors that first generation students looked for work experiences to help explore possible occupational outcomes. Another major difference between the two groups of students was that traditional students linked their majors to multiple jobs in an occupational area while first generation students linked their major to specific occupational positions.

While there has been a large amount of research in the United States using Bourdieu's theory to examine how micro processes of language and teacher's expectations are utilized to maintain social stratification in K-12 education, there has been little research done on the micro processes that occur in college that lead to the reproduction of social class. This thesis illustrates how family background-based advantages that lead to differences in students' K-12 success actually continue after they enter higher education. By drawing attention to the importance of how familybackground impacts major and career choices for community college transfer students after they arrive at the university, this thesis contributes to Bourdieu's explanation of how education at all levels contributes to the reproduction of a socially stratified society. 


\section{Dedication}

To my Great Grandpa Luther James Shelton, who taught me that a man could be many things to many people in a lifetime, and to never give up on my dreams. 


\section{Acknowledgements}

During my time at Portland State University, I have had the pleasure and honor of meeting and working with many dedicated and brilliant people. In addition, the support I have received from my family and friends has been crucial in my success.

I would first like to thank Dr. Pete Collier for his guidance and advice over the past few years. I will miss our walks to class and conversations. His patience and consistent willingness to challenge me pushed me to completion. I owe a debt of gratitude to Dr. David Morgan for his time and insights on methodology and for inspiring me to think outside the box. My sincere thank you goes out to Dr. Joan Jagodnik for our conversations, both sociological and causal. I would like to acknowledge the Sociology Department of Portland State. Specifically, I want to acknowledge Bahar Jaberi, who makes sure everything stays on track. I want to express my appreciation for the warmth and support of the faculty, whom never are too busy to stop and show their interest and support.

I have had the privilege of working beside several brilliant students and I will treasure those connections. Their own commitments challenged me and pushed me to achieve my goals. Behind every project, there are those that inspire, provide comedic relief, and help to motivate. For me, Kym, my writing buddy and friend, who never backed away from telling me when she felt I was being a bit shortsighted, provided the laughter and motivation I often needed. I also must thank Daniel for our walks and many conversations, which helped me keep things in perspective. Additionally, Carol for her 
willingness to read pages of drafts and for supporting me in my goals. Thank you for your mentorship and friendship.

I have had the consistent support from my family and I am blessed to have their love. My mother and friend, Linda Smith, always knows when to send kind words my way and is the best listener a person could ask for. Thank you for never giving up and always being there. My father, Wally Shelton, who taught me to dream and to always keep one foot in the present and one eye on the future. To my sister and all of my family who never hesitated to wish me well and support me with kind words. To my life-brother and friend, Curt, for twenty years in which we have dreamed, failed, and succeeded. Thank you for your consistent support no matter the outcome. 


\section{Table of Contents}

Acknowledgements

CHAPTER TWO: REVIEW OF THE LITERATURE ..................................................... 7

Understanding Social Class- the use of SES in major and career choice research ................... 7

Community College Transfer Student Issues ............................................................ 8

Effects of Social Class on Major and Career Choice ....................................................... 11





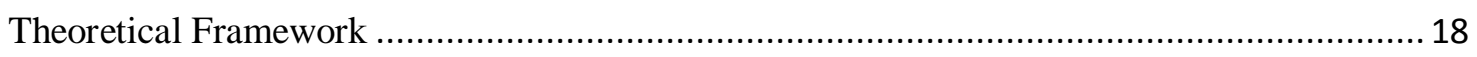

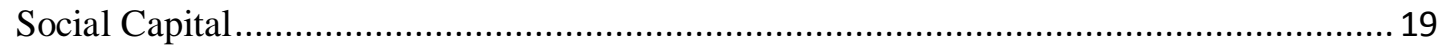

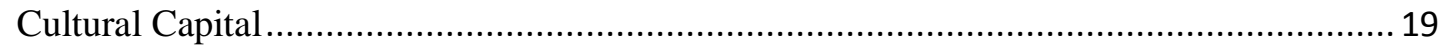

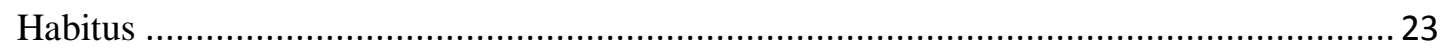

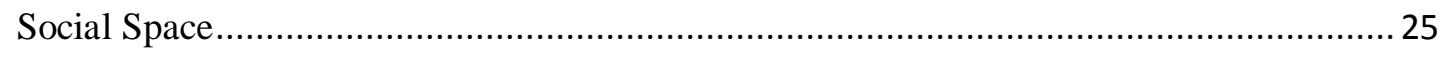

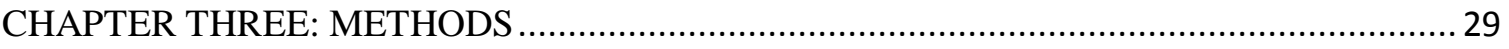

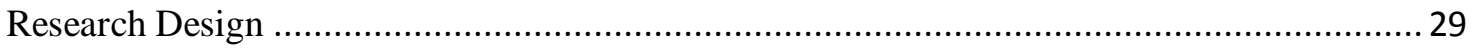

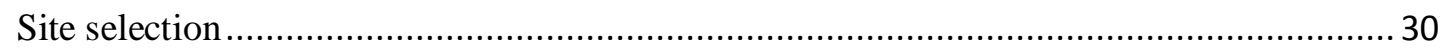

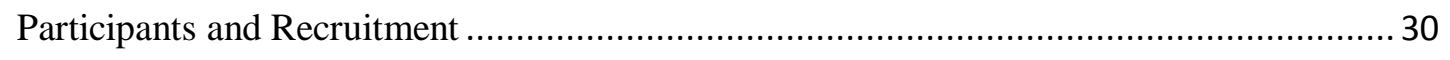

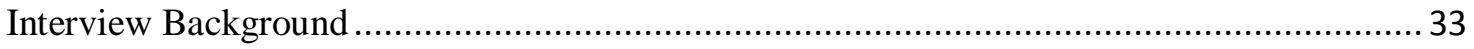

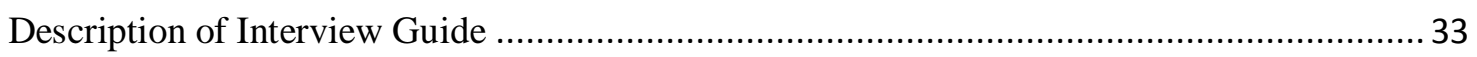

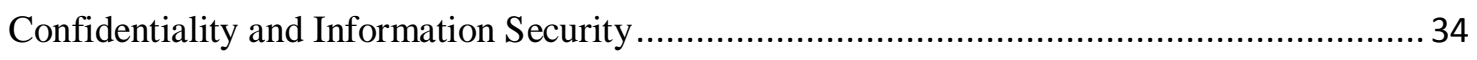

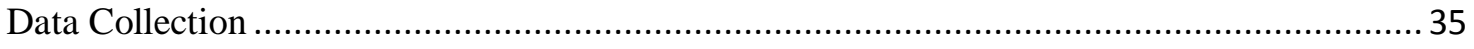

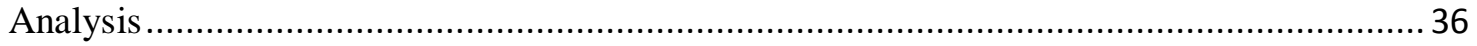

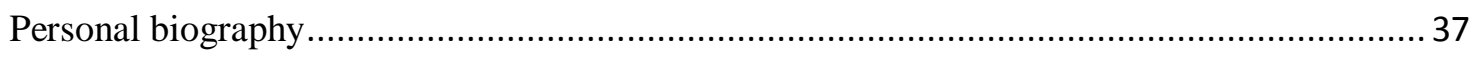

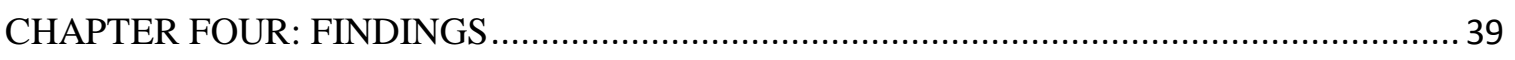


Research Question 1: How do students understand their choice of major?

Over-arching research question

Theme 1: Students' majors did not change once students transferred to the four-year university

Theme 2: Academic experiences influenced students' major choices.

Research Question 1a: How do students understand how work relates to their choice of major?

Theme 3: Work Experience influenced major choices of traditional students. .47

Theme 4: Work experiences did not directly influence first generation students' major choice 50

Research Question 1b: How do students understand how mentoring affects choice of major? 51

Theme 5: Mentoring provides $1^{\text {st }}$ generation students with help with course planning in order to complete chosen majors.

Theme 6: Mentors validated $1^{\text {st }}$ generation students' abilities to complete advanced coursework in specific majors .53

Summary for Research Question 1 54

Research Question: 2: How do students understand their career aspirations? 56

Over-arching research question .57

Theme 1: Both groups of students acknowledged that family background influenced their career aspirations. 57

Theme 2: Family experiences influenced each group's career aspirations in a different way.

Research question 2a: How do students understand how work relates to occupational aspirations?

Theme 3: Both traditional and first-generation students shared that paid work influenced their career aspirations.

Theme 4: Work experiences influenced each group of students' career aspirations differently.

Research Question: 2b: How do students understand how mentoring affects their occupational aspirations?.....

Theme 5: Both groups of students acknowledged that mentoring influenced their career aspirations.

Theme 6: Professors and academic advisers mentored first generation and traditional students 
Theme 7: Traditional students received additional support from parent and employer mentors.

Theme 8: Traditional and first-generation students valued different types of advice from mentors

Summary for Research Question 2

Research Question: 3: How do students understand the connection between their choice of major and career aspirations?

Theme 1: Many students linked current majors to getting into and completing graduate programs that would then lead to desired careers.

Theme 2: Traditional and first generation differed in how they linked completing their degree with their career goals.

Summary for research question 3

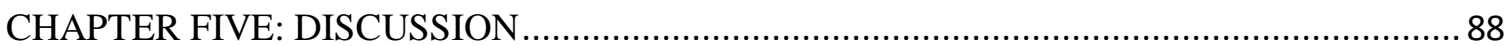

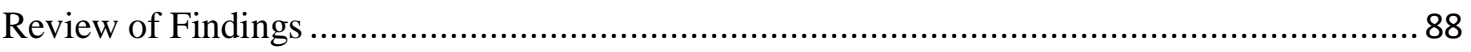

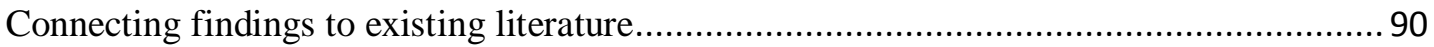

Connecting findings to the theoretical framework .................................................... 101

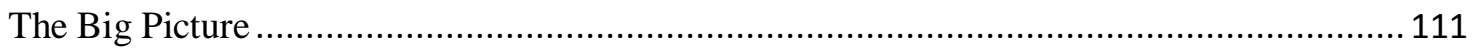

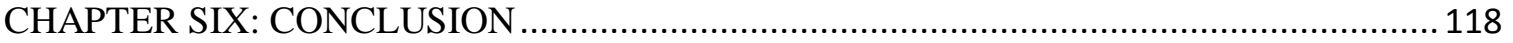

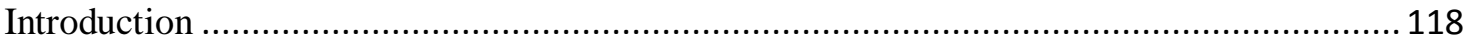

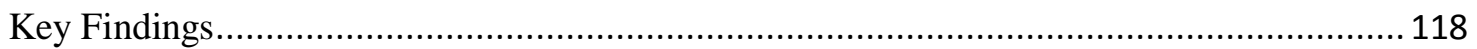

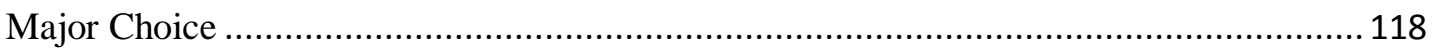

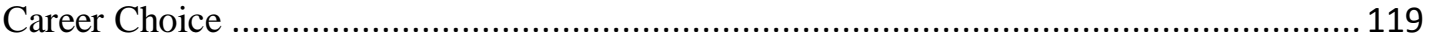

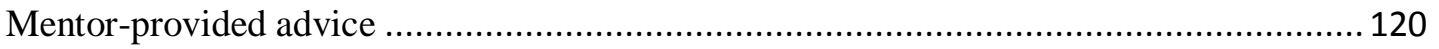

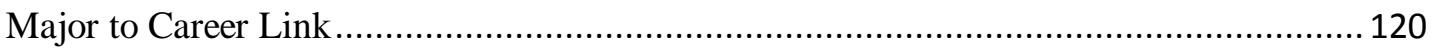

Micro-processes of major and career choices ........................................................... 121

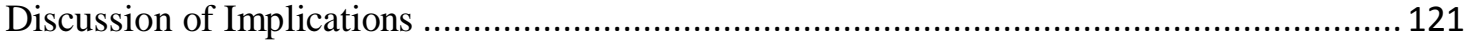

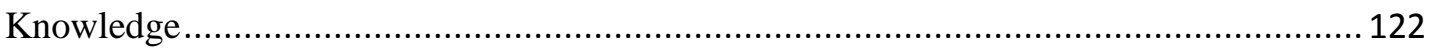

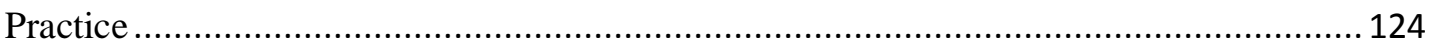

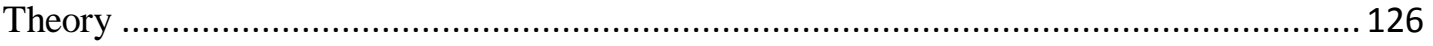

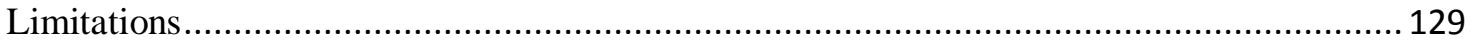

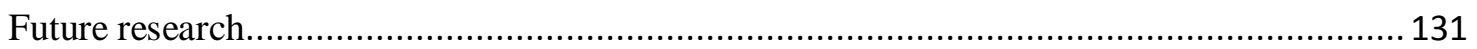

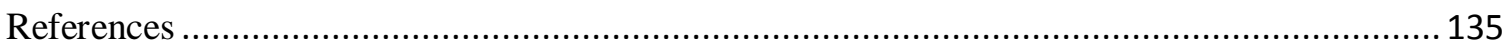


Appendix Interview Guide . 


\section{List of Tables}

Table 1: Major Choice by Student Group ..............................42

Table 2 Type of Graduate Program by Student Group.....................77 


\section{List of Figures}

Figure 1: Similarities and differences for research question \#1,1a and 1b...40

Figure 2: Similarities and Differences in impacts on career aspirations for Research

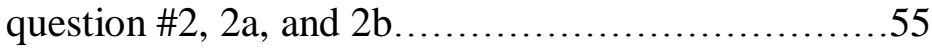

Figure 3: Similarities and differences of findings for research question \#3...76 


\section{CHAPTER ONE: INTRODUCTION}

For those that are college bound, creating a successful career path starts with the process of choosing an academic major that can be linked to a job with stable employment. There is a direct link between educational level and employment opportunities (Postsecondary Opportunity, 2011). Pierre Bourdieu argues that education, along with family, is the primary contributor of non-economic means to better life chances and thereby improve one's possibilities for social mobility (Weininger 2005). An illustration of this is the May 2012 U.S. unemployment rate, which for new college graduates was $6.8 \%$ as compared to a rate of $24 \%$ for new high school graduates. Even though individuals who have earned a Bachelor's degree or better constitute approximately one third of the total workforce, they have gained over $50 \%$ of the jobs created during the economic recovery ${ }^{1}$ (Carnevale, Jayasundera, and Cheah, 2012). While earning a college degree can help improve a person's employment potential, the focus of degree a student earns also makes a difference (Berger 1988; Arcidiacono 2004). For example, 2009-2010 unemployment rates are relatively low for recent college graduates who majored in Healthcare and Education (5.4\%), Psychology and Social Work (7.3\%), as well as Life and Physical Science (7.7\%), particularly in comparison to those who majored in Architecture (13.9\%), Fine Arts (12.6\%) or Commercial Art and Graphic Design (11.8\%) (Carnevale, Cheah, and Strohl 2012). Creating a successful career path starts with choosing an academic major that links to a "good job." In addition, whether a student goes directly to a four-year university or starts at a community college and then

\footnotetext{
${ }^{1}$ The time period for the economic recover referenced is , Jan 2010-Feb 2012
} 
transfers to a four-year school could affect both college major and subsequent career goals, specifically for those who are the first in their family to go to college.

The purpose of this comparative interview study is to explore how first generation and traditional college seniors, who have transferred to Portland State University from a community college, understand the process by which they choose their college major and the relationship between major choice and preparing themselves for specific occupational paths. A qualitative approach is appropriate for this study because it allows for an exploration of possible factors that may not be easily accessible through statistical analysis. "Occupational path" is defined as a self-proclaimed aspiration of what the participant envisions as their professional career trajectory after graduating from college with their Bachelor's Degree. The relationship between major choice and preparing themselves for specific occupational paths is defined as students' understanding of the factors that influence choices of majors while at PSU and educational decisions they have made in relation to their occupational aspirations. Using the narratives of those students who have lived the experience will produce rich data that could not be obtained using a quantitative approach.

This study defines the process of choosing an occupational path as that process by which a person develops an aspiration of what they envision as their professional job trajectory. The discovery of one's occupational aspiration is a complex one. Aspirations can be formed based on what one sees the dominant class achieving, juxtaposed with the reality of what one's peers and family achieves (Luttrel 1996). What one believes is possible can be a product of educational achievement as well as the social class in which one is raised (Tyson 2011). Occupational aspirations do not occur in a cultural vacuum; 
they in fact develop through the intersections of race, class, gender, ethnicity and culture (Montgomery, 2004). Aspirations make up a self-ascribed future. Where do aspirations come from and how do they manifest? One argument, based on the work of Pierre Bourdieu, is that aspirations are born from the cultural paradigm that one is living in (Reay 2004). The cultural paradigm is multi-faceted and can be perceived as a number of various expectations that originate exterior to the individual and help to create the aspirations for one's life outcomes as well as behavior patterns and belief systems (Reay 2004). For some, the aspirations and normative expectations of the society are more easily attainable. Specifically, students who have access to people and strategies that aligns with their career aspirations. In comparison, I argue that students who do not have this privilege or access to resources, while able to aspire to the normative dominate culture's view of success are at the same time limited by their knowledge of a fixed number of pathways to realize their career aspirations.

\section{Research Questions}

This research focuses on three primary research questions with two sub-questions for the first and second question:

1. How do students understand their choice of major?

a- How do students understand how work relates to their choice of major?

b- How do students understand how mentoring affects their choice of major?

2. How do students understand their career aspirations?

a- How do students understand how work relates to their occupational aspirations? 
b- How do students understand how mentoring affects their occupational aspirations?

3. How do students understand the connection between their choice of major and their career aspirations?

Research question \#1 focuses on how students understand their choice of major. A student can choose a major for a variety of reasons and those reasons may or may not be connected to that student's career aspirations. In some situations, a student may choose to change her major after taking a class that she did well in. Other times, a student could be influenced by the advice of a school advisor, professor, friends, employer, or family member. This study will provide a better understanding of how students make their major choices by inquiring into students' understandings of the process. Research question \#1a and \#1b focus on how work experiences and mentoring impact the major choice process.

Research question \#2 focuses on how students understand their career aspirations. A student may change his career aspiration over time after experiencing different academic classes or opportunities. For example, volunteering over an academic break may influence his career aspirations. Additionally a student could be influenced by the advice of a school advisor, professor, friends, employer, or family member. These influences may act independently of major choice due to the various different careers a person can have with a particular major. Therefore, addressing major choice and career aspiration in different questions will allow for a more complete exploration of the influences of each choice separately. 
Research question \#2a and \#2b focus on how work experiences and mentoring impact occupational choice. One point of interest for this study will be whether a student's career aspirations have changed over the time of their college experience, and if so, when and how. If career aspirations have not changed, what factors do these students identify as influencing them to continue with the same goals? Which factors have had the strongest influence? By inquiring about specific possible influential factors, such as work or experiences with mentors, this research seeks to discover the more salient influences on both career and major choice for the student being interviewed.

Research question \#3 focuses on the degree to which a student understands the connection between her choice of major and her career aspirations. Does the career goal shape the major choice or visa-versa? Is there a time when there appears to be little connection between the two or a moment when they both fall into synch? By inquiring into the students' understandings of how their major and career connect it is hoped that some answers will be found to these questions.

This thesis is organized as follows. Chapter two will review the relevant literature on understanding social class, community college transfer students, the effects of social class on major and career choice, first generation student issues, mentoring and student success issues, , and Pierre Bourdieu's Theory of Social Reproduction and Cultural Capital (Bourdieu 1974 ; Bourdieu 1984) - particularly the concepts of social capital, cultural capital, habitus and social space - as its conceptual framework. Chapter three focuses on the methodology used in this study, including the research design, site selection, participants, data collection, and analysis. Chapter four will present the findings of this study in regards to themes organized under each research question within 
and between the two groups being studied. Chapter five will discuss the findings in relation to the relevant literature and the theoretical framework used for this study. Chapter six will review the key findings and discuss the implications of this research for knowledge, practice, and theory. Additionally, this final chapter will present the limitations of this study and provide suggestions for future research.

This first chapter introduced the research topic and placed this study into a relevant social context. In addition, this chapter presented the research questions for this study and the organizational structure of this thesis. The next chapter will explore the research literature relevant to this study. 


\section{CHAPTER TWO: REVIEW OF THE LITERATURE}

This chapter will examine the literature relevant to this study and the theoretical framework used in this research. Specifically, this chapter will review the literature on the use of social economic status on major and career choice, community college transfer student issues, the effects of social class on major choice, first generation student issues, as well as mentoring and student success issues.

Understanding Social Class- the use of SES in major and career choice research

This research explores the influencing factors involved in community college transfer students' major and occupational choice as understood by the students themselves. While past research has concentrated on major choice by gender or social economic status (Leppel, Williams \& Waldauer, 2001; Ma, 2009; Montgomery, 2007; Aries \& Seider, 2007). Other studies have explored the link between occupational pay and major choice (Cebula and Lopes 1982; Montmarquette, Cannings, \& Mahseredjian 2002; Robust, 2007). Still others have analyzed student's majors and occupational choices as being connected to Social Economic Status (SES). Studies that have utilized SES have conceptualized SES as a composite of family income, parental education, and parental occupational status. Typically, SES is created as an index of several different variables e.g. (Ma 2009). Common variables that are often included in this index are family income, parental education level, and parental occupational status. Other studies conceptualize SES as family income when creating categories of students to analyze e.g. (Aries and Seider 2007). In other studies, parental occupational status is used as the basis 
for determining SES e.g. (Leppel, Williams, and Waldauer 2001). I will be using a conceptualization of SES based on parental education level. This conceptualization of SES is appropriate for this research as I am focusing on how first generation community college transfer students understand the process by which they decide upon a major and occupational path, a process that is likely to be influenced by parents' educational level.

\section{Community College Transfer Student Issues}

Whether a student goes directly to a four-year university or starts at a community college and then transfers to a four-year school could affect both college major and subsequent career goals. There are both advantages and disadvantages to beginning higher education at a community college (CC). One advantage to starting at a $\mathrm{CC}$ is that tuition is relatively inexpensive compared to that at a four year university (Kane \& Rouse 1999). Another advantage for students beginning at a $\mathrm{CC}$ is a greater scheduling flexibility due to CC 's policy of offering courses at times (e.g. evenings, weekends) that better fit the schedules of working students and those who have significant outside demands on their time (Inman \& Mayes 1999).

However, students who begin at a CC may also be disadvantaged compared to students who begin at a four-year college or university. CC transfer students, as opposed to native freshmen who begin at a four-year school, must deal with several issues relating to understanding how major choice connects to career aspirations, and what specific skills are necessary to prepare oneself for a particular career. One issue is that CC transfer students' perceptions of their current levels of key major-related skills (e.g. level of mathematics skills for engineering majors) may not match the expected skill levels for 
university students with the same major (Townsend and Wilson 2006).

This lack of match between perceived and actual skill levels, along with the pressure they feel to do well academically, contributes to the anxiety many transfer students experience after transferring to a four year university (Terenzini et al. 1994; Townsend and Wilson 2006). Transfer students can be especially susceptible to anxiety due to a lack of confidence in their academic skills. Many students who move directly from high school to the university build upon the validation of their skills they received in secondary and primary school. Therefore they feel confident in regards to their academic abilities, many students who begin at a CC and then transfer have lower levels of confidence due to differences in experiences $^{2}$ (Terenzini et al. 1994;Townsend and Wilson 2006). This anxiety and associated lower level of confidence in academic skills can be factors that affect whether students complete their degrees after transferring to at the university (Terenzini et al. 1994). Lower levels of confidence in academic skills may also result in these students changing their major as well as subsequent occupational goals after transferring to the university.

Several other CC transfer student issues are related to their differences from native freshmen in regards to the amounts of time they spend on campus and how successful they are in figuring out the most effective ways to navigate the university both in regards to the physical campus and where to locate needed support services (Townsend and Wilson 2006). For example, CC transfer students have, at best, two to three years to gain

${ }^{2}$ Grimes (1999) reports that of the 500 community college students in her study ,both traditional and first generation students, had a 3.0- 3.5 high school GPA with first generation students earning a lower GPA as compared to traditional students. Furthermore, Perin (2006) reported on the struggle that many community colleges have trying to educate in the face of the remediation needs that are often prevalent within the community college student body. Part of the possible reason for a high number of students in need of remediation services is the open-door policy that most community colleges have in regards to admissions. 
critical information about how the university and their academic departments of choice work, while students who started as freshmen at a four year school typically have five or six years to complete the same task. One way this difference in time on campus can be important for student success has to do with students' efforts in trying to schedule classes that are crucial to completing their major and achieving their occupational goals. Many required classes are not available every term; not knowing this could delay a student's graduation. Additionally, some classes may have prerequisites that need to be scheduled and coordinated with when they are offered during the year. Students who have spent a longer time on campus may be more likely to know how to complete required sequences of classes in efficient ways; this is information that transfer students may not know.

Another issue related to $\mathrm{CC}$ transfer students' limited time at the university has to do with their ability to develop meaningful relationships with faculty. It takes time to develop a good enough rapport with a faculty member to obtain their support (Townsend and Wilson 2006). Faculty can help students realize their career aspirations in several ways. For example, they can be sources of valuable information about specific majors. Many times faculty members serve as gatekeepers, connecting students to internships and other opportunities to learn more about students' chosen occupations. Faculty can also provide useful letters of recommendation when students apply for scholarships or graduate school. To develop important professional relationships with faculty takes time; unfortunately, this is a resource that is limited for transfer students (Townsend and Wilson 2006). 


\section{Effects of Social Class on Major and Career Choice}

Students' choices of major affect the range of jobs they are qualified for as well as their future earnings (Robst, 2007; Carnevale, Cheah, \& Strohl 2012). Literature exploring the major and occupational choices of college students often employs socioeconomic status (SES) as a criterion to understand the variation in students' choices.

Aries and Seider (2007) conceptualized SES as family income and used SES to create two categories of students: high income and low income. Using these categories, Aries and Seider (2007) found that students from higher income families tended to aspire to occupations that matched that of their parents' pay and prestige levels while students from lower income families seemed to choose careers that were slightly above their parents but not as prestigious or high paying as those of their higher income peers.

Ma (2009) reported that students from lower SES families ${ }^{3}$ tended to pick more secure majors that could lead to jobs that had good employment opportunities. Leppel, Williams \& Waldauer (2001) found that for both males and females, as $\mathrm{SES}^{4}$ increased the likelihood of choosing a major in humanities and social sciences increased while the likelihood of choosing a health major decreased. While the majors chosen by low SES students may be perceived as "safe", these majors lead to career paths that require very specific skill sets. An unforeseen consequence of making "safe" choices is that these

\footnotetext{
${ }^{3} \mathrm{Ma}$ (2009) conceptualized family SES as a composite measure that included both parents' years of education, the Socioeconomic Index score of their occupations, and annual family income, all equally weighted (219).

${ }^{4}$ In other research, Leppel, Williams \& Waldauer (2001) conceptualized SES as the "socioeconomic status percentile of the student's family, (in the form of) a continuous composite variable created by NES" (380).
} 
types of jobs are more subject to the supply and demand of the market than are jobs that are open for students with majors that encompass a more general skill set (Robst, 2007).

Parental educational attainment was used as an indicator of SES by Johnson and Mortimer (2011) and was defined as "[...] as a series of dichotomous variables distinguishing at least a four- year degree, some postsecondary education and a high school degree or less"(1245-1246). This variable was used to determine the strength of extrinsic and intrinsic orientations on occupational attainment. Johnson and Mortimer (2011) found that students from families with high parental education attainment did not have as strong extrinsic orientations as compared to parents of lower educational attainment. Their findings also indicated that, contrary to past studies, the influence of intrinsic orientations upon students from families with lower levels of parental education may be strengthening, (Johnson and Mortimer 2011). These researchers also argue that an intrinsic orientation may be something that is garnered while students are in college or, minimally, that students may get more exposure to an intrinsic orientation within higher education.

First Generation student Issues

Parental education is another form of social class and while CC students experience barriers in the process of transferring to four-year universities, these barriers are particularly problematic for first generation CC transfer students. A first generation student is defined as; "any student who does not have a parent who has graduated from a four year university in the U.S." (Pascarella et al. 2004). First generation students come to college with relatively lower levels of academic skills and knowledge on how to find 
information and resources to succeed in higher education (Terenzini et al 1996). Because of their families' lack of familiarity with higher education, first generation students are not as likely, as their peers from more educated families, to have the knowledge of how to connect one's educational path, major choice, and career aspiration in a way that will result in a "good job." First generation CC transfer students may have a particularly difficult time making a successful transition from the four-year college to their chosen career because they lack the fundamental knowledge about how the university "works".

Many studies have looked at the barriers that first generation students face while in college and the transition from high school to college and on to college completion (Collier and Morgan 2008); London ,1989; Byrd, 2005; Gibbons and Shoffner, 2004). By looking at how first generation students understand their own choice of college major and career aspirations, this research builds upon past research. These past studies have shown that there is a difference in the way first generation students are socialized to interact with the world around them when compared to those who have a parent(s) who have graduated from college (Collier and Morgan 2008; Lareau and Horvat 1999; Lareau 2003). College students are faced with the need to understand how to use higher education to realize their occupational goals; however, based on prior research, first generation students may be less likely to have people in their lives that can offer those examples of how to apply higher education to obtain their occupational goal. 
Mentoring and Student Success Issues

Students face a variety of decisions they must make in relation to their major and career choice. Some choices relate to requirements such as how to create a class schedule to ensure they take the appropriate classes for their degree. Other decisions may be more subjective and can include how to work in groups, manage ones time or how to approach professors.

In previous sections in this chapter it has been reported that past research has shown that, for community college and first generation students, there can be a lack of "college knowledge" needed to be a successful student (Collier and Morgan 2008;

Terenzini et al. 1996). All students, whether they are first generation or traditional, must discover how to make decisions and navigate the collegiate system. In addition, transfer students often encounter additional barriers compared to non-transfer students (Terenzini et al. 1994; Townsend and Wilson 2006). For those transfer students coming from a community college the lack of advising they may receive can compound the problems these students face at the university. Scott-Clayton (2011), reports that assistance via advising, due to adviser -student ratio, can be low while a student is at the community college. Additionally she reports that:

In some cases, family and peer networks may compensate for a lack of formal guidance. But students at community colleges are disproportionately first-generation student college-goers, many from minority and low-income families, they may be less able to glean information from the experiences of their family and friends. (1)

Once a student gets to the university, they may not have had the needed advising to efficiently choose their major, career and make a link between the two. This can result in taking classes they do not need or a delay in declaring a major, which in turn lengthens 
their time at the university. While some students may receive help from their family, first generation students, due to their lack of education based SES, may not be able to turn to their family for reliable information (Scott-Clayton 2011).

Mentoring, whether it is formal or informal, can assist college students in the various decisions they must make to be successful in choosing and completing their degree as well as linking it to their career aspirations. Mentoring is defined in several different ways. Jacobi (1991) discovered 15 different definitions for mentoring from studies done in education, management, and psychology research. Crisp and Cruz (2009) in a review of the literature summarized that many educational researchers did not define mentoring explicitly for their studies and instead let the participants describe the functions or characteristics of mentoring as they understood them. Jacobi (1991) offers a definition that is broad but more detailed:

Lester and Johnson (1981; cf, .Johnson, 1989) offer, perhaps the most detailed definition. They describe mentoring in the educational context as a one-to one learning relationship. They suggest the mentor is typically older than the protégé and may be a faculty member, staff member, or student. The mentoring relationship, according to their definition, has both formal and informal and informal aspects and is based on modeling behavior and extended dialogue (513)

This definition encompasses both formal and informal mentoring and suggests that the relationship is one- on- one and that a mentor can be a faculty member, a staff member, or a student. In another review of the literature regarding mentoring, Crisp and Cruz (2009) referred to studies conducted by Kram and Isabella 1985 and Zalaquett and Lopez 2006 and noted that the role of the mentor can also be performed by"'...] peers, friends, religious leaders and /or family" (528). Merging the definition of Lester and Johnson (1981; cf, .Johnson, 1989) and that of Kram and Isabella (1985) and Zalaquett and Lopez (2006) gives a more complete list of possible mentors a student could have. 
Within a college context, mentors assist student mentees in multiple areas regardless of whether the mentor is located in or outside of the university. Nora and Crisp (2007, 2009) identified four important areas:

(1) psychological and emotional support, (2) support for setting goals and choosing a career path, (3) academic subject knowledge aimed at advancing a student's knowledge relevant to their chosen field and (4) specification of a role model. (538)

Within higher education, mentors can help students with their major and career path choices as well as providing emotional assistance and knowledge that some students may need to achieve their educational and career goals.

Erkut and Mokros (1984) reported that students use mentors as role models to get academic advice. Collier and Morgan (2008) proposed that mentors could help students gain knowledge of the college culture and understand professor's expectations. As an example, Freeman (1999) reported that high-achieving African American students', regardless of SES, believed that mentoring was an important aspect of their college success. In a study of first generation and students of color Smith (2007) found that mentors and mentees entered a formal mentoring relationship "[...] because they believe they can either provide or receive important academic knowledge and resources during the mentoring process." (36). These mentoring relationships often provided students with needed social capital (Smith 2007) ${ }^{5}$.

\footnotetext{
${ }^{5}$ Social capital is the potential resources available to a social actor through their connections to durable
} groups and networks (Bourdieu, 1986; 248). 
Government-funded groups such as TRIO $^{6}$ can also provide mentoring. These programs offer academic assistance and support to help under-represented groups of students achieve higher retention and graduation rates. TRIO programs provide students with workshops to help them cope with college life and understand college adjustments issues that these students may not be familiar with due to a lack of experiencing in higher education. Laden (2000) describes how the Puente Project, a mentoring program for college students, particularly Latinas/Latinos, helps students adjust to and thrive in college.

Through cultural role modeling, gentle guiding, and coaching, the mentors assist the students to develop their self-esteem, to foster their self-confidence as academically capable students, and to nurture the emergence of an academic identity. Mentoring activities include inviting the protégés to work sites and professional meetings, visiting with them at various on- and off-campus locations, serving as guest speakers in their class, participating in other Puente activities, and attending college fairs and other related transfer activities. (90)

Through one-on-one interactions, these programs provide students with academic help as well as professional development, thereby making a connection between student's academic works and possible employment opportunities after college. Mentoring seems particularly helpful in supporting first generation college students.

This study explores how students' conceptualization of their choices of major and occupation as well as their efforts to realize educational and career goals are impacted by parental education level. The present study uses parental education level as an indicator of SES in order to be consistent with the theoretical framework used for this study, Bourdieu's Theory of Social Reproduction and Cultural Capital. Bourdieu (1986) speaks to the importance of considering resources other than economic or material capital when

\footnotetext{
${ }^{6}$ The TRIO program started as an Upward Bound program as part of the Economic Opportunity Act of 1964. It is a federally funded program through the Department of Education. (Office of Postsecondary Education 2010)
} 
trying to understand individuals' effort to achieve practical mastery in their respective social worlds.

\section{Theoretical Framework}

This research uses Pierre Bourdieu's Theory of Social Reproduction and Cultural Capital $(1974,1984)$, particularly the concepts of social capital, cultural capital, habitus, and social space as its conceptual framework. Social capital is understood as the potential resources available to a social actor through their connections to durable groups and networks (Bourdieu, 1986; 248). Cultural capital can take several forms, but this research focuses on domain specific knowledge known by elites or authorities (Bourdieu, 1986). Habitus is an internalized understanding of how society is organized and what is possible for an individual; habitus is the result of socialization and takes the form of a personal disposition that influences what an individual aspires to and how she/he acts (Weininger 2005). Cultural and social capital act as types of payment for access to resources; individuals must invest time and energy to acquire both types of capital. The concepts of social capital, cultural capital, and habitus are the determinate factors of class locations, which are situated in the social space. Social space is similar to the objective space of the world around us with distance and differentiation of objects within the space (Bourdieu 1984). Each actor is located in the social space and access to resources and life choices will vary according to their location (Weininger 2005). 


\section{Social Capital}

Social Capital represents the resources available to a person by way of associations in a strong and lasting network with other social actors; social capital can be turned into cultural capital (Bourdieu 1986; 248-249). Through the constant building and cultivating of the relationships within the network, a person can create durable connections that then provide him/her with benefits based on tapping into others' cultural capital (Bourdieu 1986). For example, consider a situation where two college students want to become social workers, which would require admission to a graduate Social Work program. For the student whose mother currently is a social worker, social capital, in the form of family connections to a local non-profit group or to other people in the social service sector could help the student get a paid internship .over summer break which in turn will look good on graduate school applications and align with her career goals. The second student is a first generation student and also uses family connections to get a summer job; in this case, her sister who works as a barista in a local coffee shop helps the student get a summer job at the coffee shop. Both students work over the summer and both used family connections to get work positions. Yet the advantage, in regards to how summer work experience facilitates realizing career goals, favors the student who has access to social capital that will best prepare her for the future.

\section{Cultural Capital}

Bourdieu's concept of cultural capital covers a wide variety of resources including such things as verbal facility, general cultural awareness, aesthetic preferences, information 
about the school system, and educational credentials (Lamont \& Lareau, 1988:155-6).

Bourdieu (1983:243) makes distinctions among three types of cultural capital: embodied, objectified, and institutionalized. Institutionalized cultural capital refers to degrees and diplomas that certify a person possessing the other two forms of cultural capital. Embodied and objectified culture capital are the types that are most relevant for this thesis.

\section{Embodied Cultural Capital}

Embodied cultural capital is the internalization of cultural knowledge. Swartz (1997) explains:

The accumulation of cultural capital in its embodied form begins in early childhood. It requires "pedagogical action": the investment of time by parents, other family members, or hired professionals to sensitize the child to cultural distinctions... The investment of inherited cultural capital returns dividends in school, rewarding those with large amounts of incorporated cultural capital and penalizing those without. (76)

Embodied cultural capital includes the knowledge of how to interact with others, particularly within institutions such as education. Children that have parents who are college educated learn at a very early age how to interact with teachers and school officials in a manner that maximizes their chances of getting what they want(Lareau and Horvat 1999;Lareau and Weininger 2003;Horvat, Weininger, and Lareau 2003). Lareau (2011) found that while all families, regardless of social economic status, supported the idea of their children getting a good education, middle class parents instilled an attitude of entitlement in their children and the option to disagree with and challenge school officials in way that asserted their needs and wants while still being accepted. The understanding of how best to navigate the educational system is strongly influenced by whether one's parents have a college education or not. The key component of this type 
of capital is time and dedication; it cannot be simply gained through one transaction (Bourdieu 1986). This is a primary difference between students that have been exposed to the accepted strategies of success in education since birth and those that only get this information after they start college.

In terms of higher education success, students of parents who have graduated from college may better understand how college works and which choices are more likely to lead to college success (Lareau 2003). While a first generation student may come from a family that has economic wealth, they could still face disadvantages adjusting to college due to having parents who do not know the education system and therefore do not have the cultural capital to pass on to their children. For example, parents that are more educated may be able to advise their children as to which classes or student clubs to join in order to access more opportunities for networking with influential others. In this way, these parents reproduce their societal advantage for their children. One of the peculiarities of cultural capital is that it allows an individual to understand and perceive the nuances of a particular social sphere that may not be recognizable to someone who does not have a life time of accumulating cultural capital (Bourdieu, 1993). Due to a lack of family familiarity with higher education, first generation students may not have this same knowledge and, consequently, may make major choice decisions based on little real understanding of what the career opportunities associated with that major really are.

\section{Objectified Culture Capital}

Objectified cultural capital is the material form of cultural capital Objectified cultural capital refers to objects or things that only someone with legitimate embodied cultural 
capital can claim. Simply possessing objectified cultural capital is not sufficient; a person must be able to also consume it, in other words be able to use it (Bourdieu 1986). For example, anyone can buy a copy of Homer's Iliad at a bookstore. However, Homer's Iliad only becomes objectified cultural capital when a student uses it in a college course about Classical literature. Something becomes objectified cultural capital when it is associated with a person who possesses a particular kind of embodied cultural capital. Otherwise, in this example, it is just a book. In this way embodied and objectified cultural capital work together.

Differences in embodied and objectified cultural capital are important and underlie many of the differences between first generation and traditional college students' experiences. In both secondary and post-secondary education there are programs designed to give first generation students a boost in cultural capital. Cultural capital is not accumulated overnight; it is not possible to easily transfer between individuals like economic wealth (Bourdieu, 1986). It takes both time and personal investment to build cultural capital; for this reason, lower levels of college-related cultural capital can be major barriers for first generation students. Differences in the amount of and types of cultural capital combine to amplify the reproductive function of capital. The more volume of any form of capital one has, and the more stable that volume is, the more potential one has to create additional capital (Bourdieu 1986;Bourdieu 1989).

College educated parents are more likely to know more about what classes or student clubs that their children should join in order to maximize opportunities to network with influential others. When parents recommend these paths of action to their 
children, they share cultural capital and reproduce their societal advantage for their children. One of the peculiarities of cultural capital is that it allows one to understand and perceive the nuances of a particular social sphere that may not be available to someone who does not have a life time of accumulating cultural capital (Bourdieu 1993). The accumulation of cultural capital and its inter-generational transference is a key factor in the reproduction of social stratification.

\section{Habitus}

Habitus is formed through the combination of one's experiences and socialization accumulated over one's life time and is the foundation from which a person decides what is possible for them to achieve(Bourdieu 1984). Swartz (1997) explains:

Habitus tends to shape individual action so that existing opportunity structures are perpetuated. Chances of success or failure are internalized and then transformed into individual aspirations or expectations, these are in turn externalized in action that tends to reproduce the objective of life chances. (103)

Habitus helps to create ones aspirations and actions but it also perpetuates the class structure. Harker (1984) writes: “[...], the habitus is constructed anew in each generation from two sources. The first source is the habitus of the socializing agents [...]." (120). the first source is where children learn from their parents what the possibilities are for them in regards to their future. The second source, Harker (1984) argues, ties to the rapidly changing society that in turn demands adaptation and new strategies. Differences in habitus reflect differences in the ways social actors view their place in the world and the possible life outcomes that are associated with their social location. Furthermore, these differences in habitus place social actors in proximity with, and direct opposition to 
other social actors with a differing habitus. This difference in habitus is manifested in the choices of different strategies for interacting with faculty and university staff in order to create a career and major plan and be a successful student. In a similar manner, differences in habitus could lead to differences in regards to understanding how major choice influences career choice, particularly concerning personal calculations of the potential costs and rewards associated with specific occupations.

The habitus of a traditional student leads that student to expect that a professor, when approached, will address the student's questions and concerns. Therefore, the traditional student will not hesitate in asking the professor for help or advice. A first generation student may not feel this same degree of comfort when talking to the same professor. For example, in regards to getting a letter of recommendation for graduate school, a traditional student, who feels comfortable with talking to their professor, may discover through the conversation the types of student information the professor needs in order to write a strong letter or recommendation. In comparison, a first generation student, who does not feel as comfortable talking to their professor, may wait until the last minute to request a letter, and not know to provide the needed background information that, would provide the professor with what is needed to write a strong letter. The result is that the first generation student receives a very general letter of recommendation that may not prove as helpful in regards to being admitted to graduate school. The habitus of the student that has parents who have a college degree allows for advantages that can affect choices throughout the person's life. It is important to remember that the development of one's habitus starts at birth and over the life of the 
person continues to develop. Thus, those that have an advantage tend to continue to strengthen that advantage.

\section{Social Space}

Class is a set of theoretical social locations and the determinate features of class location are habitus, cultural capital, social capital, economic capital. The social space in which class locations are found is similar to the objective space of the world around us with distance and differentiation of objects within the space (Bourdieu 1984). It is multidimensional and creates pockets of affiliation within each class, called fields. These fields constitute various groupings of social actors that share similar habitus wherein the social actors compete for resources with each other and others in the social space. Swartz (1997) states:

Fields denote arenas of production, circulation, and appropriation of goods, services, knowledge, or status, and the competitive positions held by actors in their struggle to accumulate and monopolize these different kinds of capital. Fields may be thought of as structured spaces that are organized around specific types of capital or combinations of capital. (117)

Occupational positions are designated to certain fields and these fields can be found in the social space. Students in college are competing for positions in a particular field that will either elevate or maintain their position in the social space. In order to be successful in these aspirations students must take actions and make choices as to how to achieve their goals. Swartz (1997) explains: "Practices occur when habitus encounters those competitive arenas called fields, and action reflects the structure of that encounter" (141). Habitus is not the sole factor responsible for practices, instead it is the intersectionality of habitus, capital and field that leads to action (Bourdieu 1984; Swartz 1997). The 
university itself is a field that students must compete in for resources. Students acquire capital in the forms of internships, positions in student clubs, status based on GPA or reputation as a result of interactions with others, e.g. professors, other students, in the field. Students chose college majors and then use their initial capital to complete degrees that constitute institutionalized cultural capital. Students then use their degrees to attain valued occupational positions. The more "college knowledge" a student has the better chances that student has for securing resources needed to be successful at the university. University success generates more capital, including certification as someone who is qualified for a specific career. Students who begin college with more social and cultural capital and know how to take advantage of college opportunities have better chances of completing college and earning degrees in major programs that qualify them for the most desirable occupations.

Each actor is located in the social space and operates in a field wherein their access to resources and life choices will vary according to their location (Weininger 2005). Bourdieu (1987) explains this relationship:

[...] agents are distributed in the overall social space, in the first dimension according to the global volume of capital they possess, in the second dimension according to the composition of their capital, that is, according to the relative weight in their overall capital of the various forms of capital, especially economic and cultural, and in the third dimension according to the evolution in time of the volume and composition of their capital, that is, according to their trajectory in social space (4).

Each position in the social space shares similar traits and "agents" in this space will form a somewhat homogenous group. Entry into this group is paid for by the combination of the three forms of capital (social, cultural, and economic) and mediated by the trajectory. The idea of "old money" or money that has been inherited from earlier generations is a good example of a strong trajectory. People with this trajectory can be more apt to be 
associated with the same types of people and they will share similar traits and mannerisms. In other words, they share a similar habitus and will recognize in others an understanding of the type of capital that designates the members of their group. Students from educated families share a habitus that includes expecting to succeed at college, complete degrees, and go on to get the jobs they aspire to.

In regards to credentials and the choosing of a major, social actors that are closer to the dominant positions in the social space will be able to predict what degrees are devalued or show signs of saturation in the workforce (Bourdieu 1984). This knowledge comes from having family members and friends that occupy positions in the social space related to certain occupational positions. Using the analogy of the social space being similar to the physical world, we can see how this can be possible. If a person occupies a space in the physical world she can be more aware of the changes that occurring in real time. In contrast, if a social actor lives miles away she can only use information that is receive via another source. Bourdieu (1984) presents the argument that actors attempting to move to different positions in the social space may make choices as to which positions to aspire to based on obsolete data as to the current value of specific credentials. Students who choose college majors based on outdated ideas about which degrees are most likely to lead to good jobs can end up with less-than-desirable outcomes. An example of this trend would be students choosing to major in education and earn teaching certificates, even as school districts are cutting current teachers' job. For many years, a student getting a teacher certification was almost guaranteed she/he would secure a good paying job, with health coverage and retirement, now that same degree no longer even guarantees a job. Additionally, those that occupy the social space specific occupations 
are associated with, know how best to create education plans that results in a degree as well as which credentials match with certain career paths. The concept of social space is very relevant to discussions of the relationship between the types of college degrees students' complete and social mobility. This is particularly useful for understanding differences between traditional students' college-to-work experiences and those of first generation students who are attempting to occupy a social space, of which they are unfamiliar.

Combining this review of the literature with Bourdieu's theoretical framework firmly establishes community college transfer students, in particular first generation students, face choices that are strongly influenced by their education-based SES. While it is possible that mentoring can compensate for first generation students' lack of "college knowledge," their social class is a substantial barrier they must overcome. The next chapter of this thesis will explain the methodology used in this study, including the research design, site selection, participants, data collection and analysis. 


\section{CHAPTER THREE: METHODS}

In this chapter, I will discuss the overall research design of this study, including site selection, participant selection, and a description of the interview guide. Participant confidentiality, information security, data collection, and analysis of data will also be covered in this chapter.

\section{Research Design}

This study utilizes a comparative interview design to explore the lived experiences regarding major and career aspirations of first generation and traditional college seniors who have transferred from a community college to Portland State University. The use of an in-depth individual interview design is appropriate because the focus of this research is the individual and her/his understandings of lived experiences. The use of a comparative design is appropriate because an underlying feature of the conceptual model used in this study suggests that variations between the influences behind major and career choice for first generation students compared to traditional students will be different. Therefore a comparative design will facilitate the understanding of the variation between the two groups (Reid and Moore 2008). To access the complexity of experiences that may have influenced occupational aspirations and major choice, ethnographic interview questions were used to access the "cultural knowledge" of the participants (Marshall and Rossman 2011:146). Flexibility was built into the design through semi-structured interviews in order to better understand participants' experiences individually(Bamball and While 1994; Montgomery 2004). 
Site selection

The site for this study was Portland State University (PSU). There are several reasons why this site was chooses for this study. First, PSU is well situated to gain access to transfer students with over $60 \%$ of the undergraduate population transferring into the university (PSU 2012c). Additionally, PSU has long been known for the number of students who work and attend classes. Lastly, PSU was an appropriate site for this research because I had access to potential participants via several key informants that proved valuable in regards to completing the project in a timely manner.

Participants and Recruitment

Participants of this study were traditional and first-generation students who:

- had transferred from a two year college and meet study-specific credit criteria

- were currently enrolled at PSU at the time of the research,

- were of senior status for the fall 2012 school year and

- have an employment history.

The following sub-sections will briefly discuss each of the selection criteria for study participants. 


\section{Transfer Student}

Participants were all students who had transferred to PSU from a community college and who had met PSU's minimum credit hour requirements to be admitted as a Junior -- i.e. a minimum of 90 transferable credits (PSU 2012b). These two criteria were used to define transfer students for the scope of this study.

Senior status at PSU

All participants had achieved senior standing at PSU -- i.e. earned 135 or more credits (PSU 2012a) -- by fall term 2012 or planned on graduating in the spring of 2013. Several participants while being of senior status did not have plans to graduate from PSU in 2013. However, it was not due to not knowing what they wanted to do but rather needed more time to meet the requirements of their chosen major.

Work experience

Participants fell into one of three categories in regards to work history.

- the student worked at least 35 hours a week while not in school (e.g. during the summer),

- The student worked a minimum of 8-10 hours of work or more per week while going to school.

or

- Had a sufficient work history before starting college

The guiding principle for these criteria was that there was enough work experience for the student to access and relate to how they understand work in 
relationship to their career goals. The focus on work experience was to explore the students' understanding of the affect work has had on the process of choosing a major and career goal.

\section{Recruitment}

Participants were recruited through the use key informants forwarding a promotional flier to potential participants. Additionally, the same recruitment flier was sent to a sample of 250 PSU seniors that was randomly pulled and sent out via e-mail by the Office of institutional Research and Planning (ORIP). Snowball sampling was also used so that initial participants could identify other likely participants they believed would meet the requirements of the study and offer potentially rich data relevant to the research purpose.

The recruitment flier used offered a link to an on-line screening survey. For this purpose Qualtrics ${ }^{7}$ survey software, as provided by Portland State University was utilized. Administering the screening survey 1) allowed for potential participants maximum autonomy while they decided to participate 2) it alleviated any pressure they may have felt to agree to participate, and 3) provided the primary investigator demographic/screening information, which enabled eligibility to be assessed (see appendix for a copy of screening survey). Once a potential participant submitted their survey response and indicted they would be interested in participating in an interview they were contacted via e-mail and scheduled for a face-to-face interview.

\footnotetext{
${ }^{7}$ Qualtrics is a software company that offers a platform to create, distribute, and analyze surveys. Access to this software is made possible by Portland State University to staff and students.
} 


\section{Interview Background}

Ten interviews were conducted with first generation students while ten interviews were conducted with students who had at least one parent with a bachelor's degree earned in the U.S. All interviews were one-on-one with the primary investigator and conducted in an office or comfortable setting on the PSU campus. Interviews lasted from 25 minutes to ninety minutes. Each interview was digitally recorded and the digital file was stored on a password protected hard dive. The interview consisted of open-ended questions and participants were given as much time as they needed to answer each question in the interview.

\section{Description of Interview Guide}

To best suit the purpose of capturing the lived experiences of students, semi-structured interviews were used. The interview guide was designed to complement this approach, while also ensuring that each participant was asked the same range of questions covering the same concepts and timeframes. The interview guide was designed to elicit responses to how the students major and career choice may have changed overtime. Questions were framed to guide the participants attention first to the past at the community college, then to the time when the student transferred to Portland State and lastly to the present. At each point, the student was asked to express what career opportunities she/he felt were tied to her/his chosen major. Students were then asked what their immediate step after completing their bachelor's degree would be. 
The next section of the guide addressed mentors, formal or informal, as well as role models that may have influenced or helped with the students major and career choice. Students were then asked to share how/if their paid work experience while going to college linked to their major/career choice.

The final section of the interview guide had the students reflect on lessons learned by asking them if knowing what they knew now they would have done anything differently. This line of questioning was applied to the each section outlined above, time at the $\mathrm{CC}$, time at PSU, current major, paid work, and choosing or identifying mentors. After all the formal questions were asked, the students were asked if there was anything else they wanted to share regarding their major and career choice, if there was nothing else the interview ended. If the student had something to share, the interview continued.

\section{Confidentiality and Information Security}

All individuals who participated in the screening survey and interview signed an informed consent form before any participation. A separate consent form was supplied for both the screening survey and the interview (see appendix). The primary investigator contacted potential participants who had already reviewed the screening survey consent form and subsequently filled out the online screening survey indicating that they were interested in the study. Those that qualified for the study were contacted by email to schedule the interview. Participants were told that the interviews would be digitally recorded and would take about 60 minutes to complete. Before a face-to-face interview began, each participant completed the interview consent form. Participants were also informed that the interview data would not be shared with anyone outside of the principle 
investigator, and only aggregated and anonymous data will be shared with the public. Only the primary investigator had access to raw data from the questionnaire and interview. Interview responses were transcribed in a timely manner with a numerical code as the only identifying information. All audio files and transcripts were maintained in secure filing cabinets and in password-protected computer files on the primary investigators PSU "H” drive, and personal computer for the required amount of time.

\section{Data Collection}

A semi-structured interview was used to collect data in this study. Because the focus of this research was on students' understandings of the their lived experience, this method of data collection was appropriate for this study because it gathers data in ways that allows participants to disclose, in their own words, the way each one sees and understands the telling of those experiences (Marshall and Rossman, 2011:144). This approach to interviewing relied on followup questions or probes to access rich data that may have been lying below the surface of participants' initial comments (Patton 1980). Initial questions and probes were based on the literature and were developed beforehand. Using a semi-structured interview design allowed for areas of interest that were bought up by the student but that were not anticipated beforehand to be taken up and discussed. This approached maintained flexibility in regards to the wording and ordering of the questions and probes in the interview guide. Additionally, the research design allowed for the adjustment of questions and probes over the duration of the data collection process to ensure that the research questions were answered in the best possible way. 
Analysis

I transcribed each recorded interview verbatim. Additionally, recorded interviews were listened to one to two times each before or after they were transcribed which helped familiarize myself with the data and allowed themes to emerge. Initial codes were based on existing literature as well as Bourdieu's Theory of Social Reproduction and Cultural Capital. I remained flexible in the building of codes - as data was collected, code categories and labels were created as new information was incorporated into initial categories. Final codes reflected the student's understandings of the relationship between mentorship ${ }^{8}$, paid work experience, attending classes at a community college, and transferring to Portland State to major and career choice. Returning to the theoretical lens used for the study, the relationships that were recognized were then linked to theoretical concepts, specifically that of habitus, cultural capital and social capital.

Additionally, thematic analysis was used in order to identify themes and patterns amongst the data collected. Themes were analyzed within groups, first generation students and non-first generation, respectively, and then compared between groups. This method of analyzing allowed for similarities and differences to be detected.

Dedoose, a cross-platform application, was used to improve the efficiency of coding, organization, searching for data, as well as for identifying themes. Dedoose offers easy to use tools to facilitate the coding process as well as tools to help with initial analysis. Specifically, the use of word clouds was used to identity codes that were used

\footnotetext{
${ }^{8}$ Mentorship is considered to be a formal or informal relationship with an experienced person in a particular area of life that offers advice and support. The term role model was also used to help students identify particular people of influence in their lives as it relates to their choice of major and occupation.
} 
the most. Additionally, Dedoose was used to sort excerpts by code. These excerpts were then analyzed by hand to add an additional layer to the process of identifying themes.

Personal biography

I am drawn to this area of study for several reasons. My personal and professional background gives me advantages as well as disadvantages. I am not a first generation student. My father was a first generation student. He instilled the importance of a disciplined approach to studying in me as a young boy. As an adult, he shared with me his stories of being a first generation student and some of the difficulties that arose for him both in school and later after, he entered the professional world. I have since worked with many students who are the first in their family to go to college. I spent a number of years in the work force before I decided to come back to college and complete a bachelor's degree. I have lived a life of a working-class person as well as a middle-class high school student. These experiences allow me to understand, to a certain degree, both of the groups of students that I wish to interview. However, I also realize that my experiences, as well as all experiences, are unique to the individual person and the context. What my experience has taught me is to be open to new ideas and experiences from the viewpoint of the individual telling the story. There is no "right "or "wrong" story; each lived experience is important in some way to the person who lived it. This lesson and attitude was formulated in my years working in a drug-rehabilitation facility and as church counselor.

My experiences allow me to be sensitive to the views of others as well as being able to communicate effectively and ethically. I also recognize that I am a middle-aged, 
white male and despite my experiences, the attribution those I interview may make about me, based on these characteristics, may at first distance them from me. I propose to address this issue by having key informants introduce me to participating students, and through my conversations with participants, both of which will help to establish me as “genuine”. By combining this approach with my professional skills and experiences, I am confident I can conduct this project successfully, ethically and within the time frame given for a master's thesis.

This chapter has described the research design used for this thesis including a detailed description of the participants, setting, recruitment, and interview guide. Additionally, details were given in regards to the process used to analyze this data. The following chapter will introduce and detail the important findings, which resulted from the analysis of the data collected. 


\section{CHAPTER FOUR: FINDINGS}

This chapter will present the findings of this research. First, key variables and the timeframe used for analysis will be clarified; then the findings for each of the three research questions will be presented.

\section{Clarifying variables}

There are two important aspects of the study to clarify, the operationalization of key variables; and the period in students educational careers used for analysis. First, beginning major and career goals are operationalized as the major and career goals that students reported having when they started at the university; current major and career goals are those that students reported at the time of the interviews. Second, one element of the theoretical frame used to analyze these data is Bourdieu's concept of habitus. All of these students have transferred from a community college to the university. Bourdieu's conceptualization of habitus would suggest that class-based differences in habitus would be most apparent during these students time at the four-year university. It is at the four-year institution that these community college transfer students must make their final decision in regards to major choice. Additionally, it is at the university that students will be the clearest as to the link between their major and career goal. Making and finalizing major and career choices relies on understanding the university culture of higher education. Comparing stories of how first generation students and traditional students understand their choices of major and career after having transferred to the 
university gives the opportunity to explore possible differences in the types of resources that are the most influential. Some students, not being acquainted with the culture of higher education, would have to rely more on previous ideas about "what is possible for someone like me." Therefore, this study is looking at the period after the students have transferred to the university.

The overarching question driving this research is how first generation and traditional community college transfer students understand their choice of major and career as well as the link between major choice and career goals. In the next section, the similarities and differences in the two groups of students' responses will be presented for each research question. Please note that the identified themes capture ideas that were expressed by multiple participants. Specific quotes from the interviews will be used to illustrate the themes and to draw attention to similarities and differences in the two groups of participants' responses.

Research Question 1: How do students understand their choice of major?

Research question number one has three parts. The first sub-section presents the findings for the over-arching research question: how do students understand their choice of major? Subsequent sub-sections present the findings for research questions $1 \mathrm{a}$ and $1 \mathrm{~b}$. Research question 1a explores the effect of paid work on major choice. Finally, research question 1b explores how students' mentoring experiences influence their career aspirations. 
Figure 1 shows the differences and similarities for research question 1,1a and $1 \mathrm{~b}$.

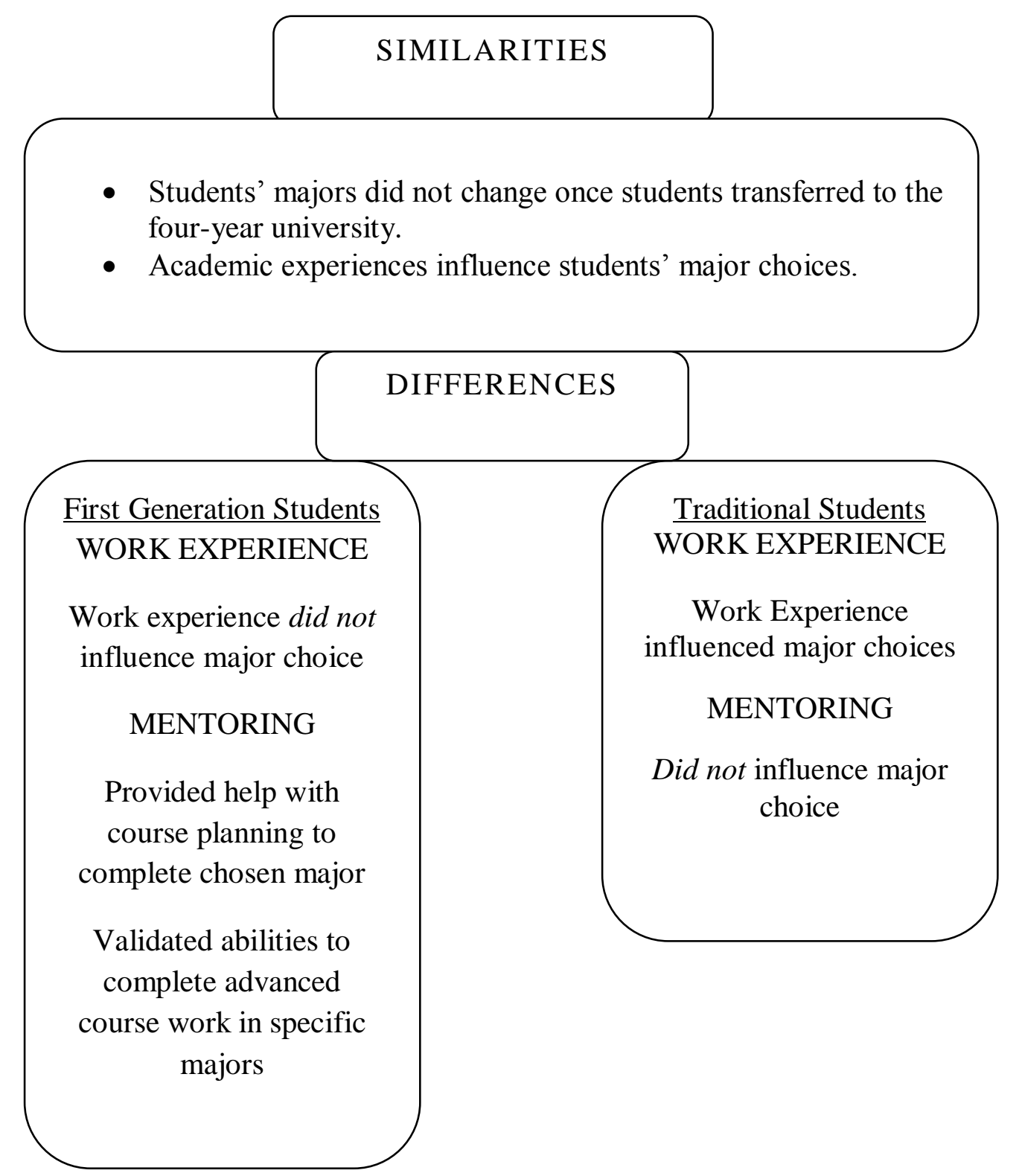


Over-arching research question

Theme 1: Students' majors did not change once students transferred to the four-year university

The majority of students, regardless of whether a participant was first generation or traditional, did not change their major after transferring to the university. This is not surprising when the structure of the collegiate system is considered. These students are attending a university that highly encourages all students to declare a major by their junior year. Most of these students came to the university as a junior or during the last term of their sophomore year. Additionally, many programs at the university only allow declared students to enroll in major-required classes. Therefore, students are structurally required to declare a major and to begin work on the needed major requirements if they wish to graduate in a reasonable amount of time. While many of these students went through periods of exploring different programs and switching majors before transferring to the university, by the time of the study their choice of majors had solidified. 
Table 1 Major Choice by student group

\begin{tabular}{|c|c|c|c|}
\hline Name & $\begin{array}{c}\text { Beginning Major at } \\
\text { PSU }\end{array}$ & $\begin{array}{c}\text { Second Major } \\
\text { at PSU if } \\
\text { applicable }\end{array}$ & Current Major at PSU \\
\hline $\begin{array}{c}\text { First } \\
\text { Generation }\end{array}$ & & & \\
\hline Jasmine & Psychology & & Psychology \\
\hline Christa & Psychology & & Psychology \\
\hline Tera & Geology & & Philosophy and Community Health \\
\hline Anne & Speech and Hearing & & Criminal Justice \\
\hline Bella & Criminal Justice & & Speech and Hearing \\
\hline Laura & Speech and Hearing & & BS in Social Science \\
\hline Monica & No declared & & Engineering \\
\hline Liz & (CC) accounting & & Molecular Biology \\
\hline Zach & Engineering & & Sociology \\
\hline Jade & Molecular Biology & & Criminal Justice \\
\hline Traditional & & & Business Management \\
\hline Craig & Civil Engineer & Math & Psychology \\
\hline Kevin & (CC) AA in & & Psychology \\
\hline Holly & (CC) AA in Project & & Poly Science \\
\hline Maria & Psychology & & Public Health \\
\hline June & Psychology & & Sociology \\
\hline Lance & Poly Science & & \\
\hline Patt & Public Health & & \\
\hline Judy & Science & & \\
\hline Cyndi & English & English & \\
\hline Rose & Psychology & & \\
\hline & & & \\
\hline
\end{tabular}

Theme 2: Academic experiences influenced students' major choices.

Another similarity between the two groups of students had to do with how they chose their current major. One common theme for both traditional and first-generation students was that academic experiences influenced student's choice of major. For some students the introduction to the subject that eventually became their major happened before they enrolled at the university; others only discovered the subject that became their major after they reached PSU. 
Anne, a first generation transfer student, had been pursuing a career in the medical field since early in high school. However, she took a sociology class that increased her interest in the area when she first started college at the community college. She is a sociology major and is planning to apply to graduate schools in sociology after she graduates next year.

I got my first taste of sociology when I in my first actual year at the CC. I was 18 it was an intro class. I don't know what happen to me I was like oh my gosh, they don't offer that in high school they don't offer any sociology classes in high school you don't have any, you get psychology, I was like this is stupid... I took my first Soc class; I was like I want to see what else this has to offer I want to see what else this has. So they wouldn't let me take the classes I wanted to take, so I had to change my major to take the classes that I wanted to take, I didn't even change my major because I was going to pursue sociology, I changed it so I could take those classes, I was being sneaky.

-First Generation Student Transfer Student

Anne stated that taking a sociology class sparked her interest. Although she originally switched her major to be able to take the sociology classes that interested her she eventually fully committed to earning a degree in sociology.

Taking courses can serve to introduce a student to a field or help a student realize that she may not want to pursue that subject matter anymore. Taking business classes led Rose, a traditional transfer student, to question her choice of major. While she had worked in the business world a long time, after she took the business classes at PSU she realized that perhaps she wanted a change.

I took an intro to business course and that's what showed me I did not want to do business it was good and while the teacher was amazing and the class was great too, it was what I had been doing every day for the last five years. I am sitting in class and going over the textbook and I already knew a lot of this stuff. I had done gross profit margins before and things like that and I thought you know I just don't want to do this anymore; this is not interesting to me. I am good at it but I do not want to do it

-Traditional Transfer Student 
A reaction to specific types of academic course work can also lead a student to decide that the subject is not for her. From the student's perspective, the choice is not due to academic difficulties, but simply to deciding that the subject is no longer of interest.

Monica, a first generation transfer student, is pursuing a Bachelor's degree in Social Science. The graduate school program to which she is applying does not require an advanced background in statistics or a specific major. Therefore, she has a lot of leeway to choose a major that she felt was right for her.

This may sound bad but I hate math. [Laughter] ...I saw what kind of degree could I get without taking more math and I was really close to the social science [degree]. One of my weak points was math, I didn't want to take more math, and as I took more classes, I found that the classes that I was very interested in were all falling under social science, anything that has to do, like History or Black studies or Chicano/Latino studies all were under that social science group. I think for me for it just helped me. They are all classes that are geared toward teaching you about the people around you and it sort of fell into place.

-First Generation Transfer Student

Monica's story illustrates two different forms of influence stemming from her experiences with classes. First, she recognized that her math skills were not something she wanted to work to develop to the level she would need to earn a degree in sociology. Second, Monica found a set of classes that she was interested in and believed that these classes would help her with understanding people better.

Christa, a first generation transfer student, is currently a psychology major and is planning to go to graduate school. Christa developed an education plan that would prepare her for nursing school. She had begun to question this plan in her second year at college. She indicated that she became a psychology major in no small part due to a class she had taken. 
Yes, I was kind of on the fence as to what I was going to do and took one of my 200-level [introduction to] psychology classes, my teacher was a forensic psychologist, and we did case studies on actual patients that she has done evaluations on. In addition, I became fascinated with forensic psychology and what was involved and that class is what made me change over to psychology.

-First Generation Transfer Student

Christa's academic experiences in a psychology class led her to want to learn more about the subject and possible career paths.

In this section, Theme 1 showed that for the majority of students there was no change in major between the beginning major and current major choice. Theme 2 illustrated the influence of academic experiences on current major choice. Some classes offered enough difficulty that students reevaluated the effort needed to succeed in the major. In other cases, classes served to spur on or create interest in an area, thus leading to a change in major. Neither of these two ways in which an academic experience affected major choice was more prevalent in any one group (first generation or traditional).

In the following section, research questions $1 \mathrm{a}$ and $1 \mathrm{~b}$ will address the influences of mentoring and work on major choice. These influences are not mutually exclusive even though one or the other was more salient for certain students.

Research Question 1a: How do students understand how work relates to their choice of major?

Research question 1a will explore the influence of work experience on major choice. This influence was very salient for the traditional students. There is no discussion of 
similarities for this research sub-question because first generation students did not mention the influence of paid work on their major choices.

\section{Differences}

Theme 3: Work Experience influenced major choices of traditional students.

Ken, a traditional transfer student, stated that, going to college was a vehicle for opening opportunities in his current field. Ken had come back to school after many years. He had served in the armed forces and is currently in the Army Reserve. He has two main motivations for pursuing his current educational goals. First, a Bachelor's degree will increase his chances at promotion in the military. Second, earning this degree will help him prepare him to transition to a civilian job. Ken will be retiring from the military soon and he is looking to his future. Ken is using his GI bill benefits to go to school. Ken noted that having this monetary benefit from his paid employment had a direct influence on his educational goals.

Let's put it this way I am a warrant officer in the Army reserve. Very early on in the warrant officer program when I was going through that program, it was instilled on us that with certain grades there was a desirable education credit that went with it. I.e. W2 [Warrant Officer 2] they wanted at some point in that process of having that grade they wanted you to have your associates degrees and to make the next grade up they would like to see a bachelor's degree and for the next grade up a master's degree. I wouldn't be in long enough to have to worry about a master's degree. That was part of the process of wanting to continue.

-Traditional Transfer Student

Ken noted that completing a college degree would provide a concrete benefit concerning his current military career. However, his pursuit of a bachelor's degree also had implications for his future. He tied his major choice to a field that was familiar to him and linked well with his current work and military experience. 
Based on my military experience, [I knew] the type of things that a CCJ degree [Criminology and Criminal Justice] would benefit. Because a lot of the positions require a certain amount of experience, which I probably have or a combination of that and a degree so I am trying to cover my bases. I have looked at government web sites and some of the contractor web sites for many of the civilian jobs they have. They will look at a certain amount of experience and maybe qualify for something low or mid-level but if you want something a little but more desirable with the organization the degree is what their cut off is, from here up these are open to you with the degree, versus not having it, is from here down.

-Traditional Transfer Student

Ken linked his major choice with his current employment. His work has helped to fund his education. His military service has also allowed him to gain experience that he now wishes to strengthen by earning a degree that relates to his current work and future occupational options.

Hanna, a traditional transfer student, is using a tuition assistance program via her employer to earn her degree. Hanna's manager encouraged her to go back to school and get a four-year degree in business management. Additionally, Hanna plans to get an engineering degree after she completes the Business Management program. Hanna chose this combination of majors to help her get a better position at her current job and align with additional personal career goals.

However, my part of the plan is to eventual double major in engineering... That was not the plan with the manager but it is part of my personal plan... [Engineering] is also somewhat associated I actually have been in engineering support and doing some levels of engineering from pretty much since high school. I was a Black Hawk helicopter mechanic right out of high school in the US Army. I have been with electric testing companies for ten years or so doing engineering electrical testing, reading schematic and things like that all the way up. My current position I got in on the administrative end but also the positions supporting an engineering group, I also do technician work for them, so the two degrees actual run parallel for me to what I do. My ultimate goal is to be a technical business manager; I want to manage technical teams.

-Traditional Transfer Student

Hanna used an opportunity she had at her current job to get further education. Hanna strategically chose her majors in order to get the credentials needed to be eligible for the 
position she wanted. Hanna shared several stories about past situations where she had the desire and ability to work in a certain field or position but did not have the credentials to do so. However, she now was using the support from her job to help her build her skills. Both Ken and Hanna are pursuing bachelor's degrees in hopes of getting increased opportunities in their current fields of work. Similarly, Cyndi's choice of major is intertwined with her current work.

Jeff- Does your paid work connect to your major or career choice?

Cyndi-Usually figures very largely in my conversation

Jeff-What you have covered so far, is how working with your current company you have been exposed to different things in your work environment that you see as not ideal. With your education, you have been able to find possible solutions to that, would say that those things you have seen in work has been a motivation for your career?

Cyndi-I think it has definitely influenced my major it has definitely influenced what I want to do and how I can go about it.

-Traditional Transfer Student

Additionally, she shared one way her experiences at her job influenced her major choice.

I was ok what do I really want to do. At this point, I had gotten really frustrated with corporate structure and dealing with problems that I did not see any one really addressing. What I need to do is talk to the managers and tell them this is what's going on and this what's going to be helpful. And so I went ok sociology I could study large amounts of people and kind of figure out what is going on.

- Traditional Transfer Student

Cyndi noted a direct connection between her major choice and her career aspirations.

For Ken, Hanna, and Cyndi, their work experience directly connected to their current college major. For Ken and Hanna, school was an extension of work; this was a main reason they chose to attend college. For Cyndi, choosing to major in sociology allowed her to better understand the dynamic in her current job as well as what she could do in the future to possibly assuage the conflicts she sees. All three traditional students in 
this section indicated a strong link between the work they have done and their current major choice

Theme 4: Work experiences did not directly influence first generation students' major choice

For first generation students, work experience did not directly influence major choice.

Those first generation students who talked about work referred to their employment as a way to pay the bills. The following sub-section shows the purpose of these students' current work.

First generation transfer student Jade works for a retail store in a mall. When asked about the link between her current work and her major she said:

Yea work, fun stuff. Not a lot to say about it, it is sort of a wired job, minimum wage, I am a cashier, I work there Friday, Saturday and Sunday, so it does not interfere with school but sometimes I do work during the week if they need me. ... I just need the money... [.laughter], I am definitely trying to switch that up this year, at hospitals or wherever so I can definitely have the experience and have the money as well. So I don't have to worry about going back to that place.

-First Generation Transfer Student

Jade's current work has no influence on her college major. Jade's current goals are to work in the medical field or as a retail pharmacist.

Anne, also a first generation transfer student, currently works at a local coffee

house. Similar to Jade, Anne's job does not link with her chosen college major.

Last year I was working about 30-35 (hours a week) and this year I was like ok I am not doing that again I am working 20-25 hours a week and I don't want to ever do that again.

...I work because I have to pay for my apartment, food, utilities, I don't get financial aid, my parents help but they do not pay for everything....it is a pay check and its gone by the end of the month

-First Generation Transfer Student

Anne is sociology major. She is currently working toward completing her bachelor's degree and will be applying to a sociology graduate program next year. 
This section illustrated the different influences paid work had on major choice for traditional and first generation students. For traditional students Ken, Hanna, and Cyndi, their paid work directly influenced their major choices and educational plans. For first generation students Jade and Anne, their current jobs served as a way to pay their bills and had no impact on their major choice. The next section will illustrate the impact mentoring had on the choice of major.

Research Question 1b: How do students understand how mentoring affects choice of major?

Research question $1 \mathrm{~b}$ will explore the effect of mentoring on choosing a major. There is no discussion of similarities for this research sub-question because mentoring did not influence major choice for the traditional students interviewed.

\section{Differences}

This section will show that mentoring had an impact on major choice for first generation students but not for traditional students. First generation students received help in the form of assistance with course planning and general support for their major choice. Students see this type of help as vital for their success and confidence with their current major choices.

Theme 5: Mentoring provides $1^{\text {st }}$ generation students with help with course planning in order to complete chosen majors.

Jade has been a pre-pharmacy major since community college. However, pharmacy schools do not require a specific major. Therefore, after transferring to the university she 
had a wide variety of majors in the hard sciences from which she could choose. The

following quote illustrates how she came to make her choice.

My adviser introduced me to DARS [the Degree Audit and Report System] and I got obsessed with that, after that I have been running DARS on my own trying to see where was in different majors and things that were interesting to me. I had a lot of biology credits already when I came in. When I came in, I had taken one year of general chemistry and one year of general biology. In the summer. I took microbiology and I thought that was interesting. I was ok, I like the biology department so far, I didn't have a lot of credits in it but it was going to be either biology or chemistry for me. But in the general science [major] I already had both so those were a lot of credits in that area of the major already and I kind of looked into the biology department and I thought I could do generally biology. I could do this in three years. It was classes that I would have to take anyways and things [this was a subject that] interested me... I then sat and looked at molecular biology and they have the upper level microbiology inclusion in the major. I want to continue to take more micro - biology. So that I kind of zeroed in on, I was hey [to my adviser] look I could be a microbiology major and she was like is that what you want to do? So we planned that out and I went to the biology department and spoke to the biology undergraduate adviser and we figured out what to do to be a bio major.

First Generation Transfer Student

Jade's mentor helped her with the major choice process by introducing her to the university's resources specifically designed to help students learn about the requirements for different majors. The Degree Audit Requirement System (DARS) can be difficult to use if not taught how to use it. Jade used this system to narrow down her major choice.

She then used her mentor / adviser's support to create the needed educational plan.

Jasmine is part of a university program for first generation students. Similarly to

Jade's experience Jasmine's mentor, the adviser in the first generation student program, helped her understand the different tracks within her chosen major as well as how to make an educational plan. Jasmine learned that choosing a psychology major offered her several options to specialize.

I pretty much, I have already decided the psychology major but she pretty much helped me to decide to do the general psychology because she was hearing hesitation from me like 'oh I like the human resource I looked at it I went to the business area, that is more business environment not psychology but then she opened my eyes that people with psychology can also major, can get a career in HR and I don't necessarily have to have a business degree but since I was being hesitant , 
I wasn't really sure if I wanted to [inaudible]. Since I have other interests, you know to work in the counseling department or mental health department.

-First Generation Transfer Student

Jasmine's mentor was able to help her solidify her major choice by tying in possible

career outcomes. Jasmine stated that she had a lot of anxiety about choosing a major, but that having a mentor to talk to about her major helped her to be more confident in her choice.

Both Jade and Jasmine reported that mentoring provided help they needed in course planning, which in turn facilitated their efforts to complete their chosen majors. Jasmine shared that she had a lot of anxiety about choosing a major

Theme 6: Mentors validated $1^{\text {st }}$ generation students' abilities to complete advanced coursework in specific majors.

Mentors gave needed encouragement to first generation students to complete their course work and enable them to complete their major program.

For Monica, the program she is in for first generation students is a vital part her college experience:

... having TRIO as a support system, by the way, I do not know if I have mentioned, their advisers are just wonderful. Having one- on- one adviser that [in addition to] your major adviser make sure you are not spending money on classes that are not counting toward your degree. [Additionally] making sure you are passing your classes and making sure, they are on you, making sure you are doing what you need to be doing, has made me that much more stronger and to finishing. It has made me want to finish it's not that I don't want to let myself down now it's that I do not want to let this program down. [A program] that has taken me under their wing and has given me every single thing that I have needed, very single tool, whether it is a computer lab or free advising or writing help or you know a place where I could call my second home basically.

First Generation Transfer Student

Mentoring from the TRIO program helped Monica in two ways. First, her mentor helped Monica to create an educational plan. Second, the support she received from her mentor 
helped motivate Monica to finish her degree program. Monica shared how her mentor's

support has assisted her while at PSU:

I cannot stress enough how much programs like TRIO and the WRC are so important for women like me. My main concern is not letting my GPA fall below a 3.9. ... She [my adviser] doesn't want me to stress. She wants me to have more confidence in myself to not have to stress over the classes. This past spring term I took two classes and I was just so stressed out. I ended up taking them pass/no pass and I ended up getting an A in one of them and B plus in the other and I was kind of glad I took them as pass /no pass because it would have dropped my GPA. I am trying graduate Suma Cum Laude. If anything these programs have made me want to succeed and made me want to do to the best I can.

-First Generation Transfer Student

Monica's experience illustrated the value of programs designed to help first generation students succeed in college. With her mentor's help in creating an educational plan, Monica has succeeded in her chosen major.

This section illustrated that mentoring had an impact on major choice for first generation students. This impact occurred in two ways. Mentoring provided Jade and Jasmine with help in planning their course schedule in order to complete their major. For Monica, her mentors validated her abilities to complete her majors needed course work. Mentors provided these students with direction, encouragement and an increased sense of confidence. While this encouragement and resulting confidence is something that all students need, it is even more important for first generation students who do not come from families with experience in navigating higher education.

Summary for Research Question 1

Research question one explored how students understand their major choices. A majority of the students from both groups did not change their majors after they transferred to the university. Additionally, taking classes in specific academic disciplines influenced 
students' major choices. The themes related to research question 1a illustrated the influence of paid work on major choice for traditional students. In contrast, paid work did not have an impact on major choice for first generation students. Research question $1 \mathrm{~b}$ examined the influence mentoring had on first generation students' major choices. Mentoring helped first generation students plan their course work in order to complete their majors. Additionally, mentoring validated first generation students' abilities to complete advanced course work specific to their majors. Mentoring did not have an impact on traditional students' major choices.

This section illustrated how students understand their choice of majors. Both first generation and traditional students reported that positive experiences in classes influenced their major choices. For traditional students paid work affected major choices. Additionally, traditional students linked their major choices to their current work and future occupational interests. College mentors influenced first generation students' major. Interactions with mentors helped first-generation students plan their paths to completing degrees in specific majors encouraged them to persist on their major paths, and helped them complete the necessary course sequences required by their major programs. By these actions, mentors both validated students' major choices and increased students' chances of completion of their chosen majors. 
Research Question: 2: How do students understand their career aspirations?

Figure 2: Similarities and Differences in impacts on career aspirations for Research question \#2, $2 \mathrm{a}$, and $2 \mathrm{~b}$

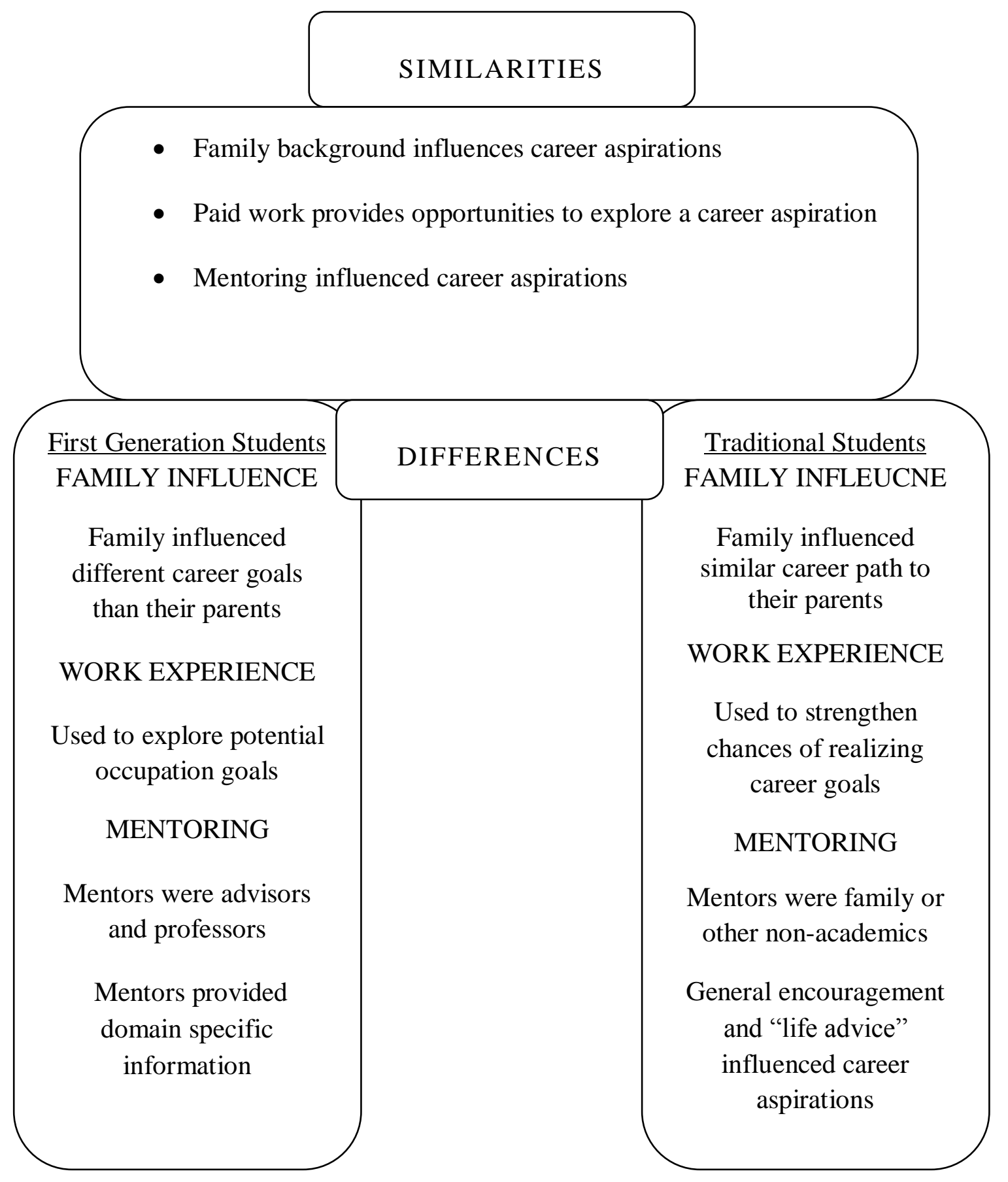


Research question number two has three parts. The first sub-section presents the findings for the over-arching research question: how do students understand their career aspirations? Subsequent sub-sections present the findings for research questions $2 \mathrm{a}$ and 2b. Research question $2 \mathrm{a}$ explores the effect of paid work on career aspirations. Finally, research question $2 \mathrm{~b}$ explores how students' career aspirations are influenced by their mentoring experiences.

Over-arching research question

Similarities

Traditional and first-generation students discussed two common themes with regards to the over-arching research question: how do students understand their career aspirations? First, both groups of students' career aspirations were influenced by their respective family backgrounds. However, how these experiences affected their aspirations were different.

Theme 1: Both groups of students acknowledged that family background influenced their career aspirations

Lance had aspired to have a lifetime career in the military since high school. However, his career was cut short and he was honorably discharged after serving five years in the Army. He felt that serving his country was very important and he plans to continue to do so. He also reported that he plans to apply to the FBI and CIA when he graduates with his degree in Political Science. His family background is a very important aspect of his career aspirations. 
Yea my Dad was retired, major, airborne instructor. My grandfather was a pilot on the air force Vietnam and Korea. My great grandfather was in the last horse Calvary in the state Oregon We could trace my family all the way back to the battle of Hastings in 1066.

Lance comes from a long line of men that have served their country and this is a very important part of his career aspirations.

Monica, a first generation transfer student, also noted that her family history strongly influenced her career choice. Monica stated that her past personal struggles served as a foundation for her occupational aspirations to work with high school and college students who themselves struggle academically. When asked how she developed her occupational goal, Monica shared a story from her childhood to explain the motivation for her current career goal of working with academically challenged youth.

My parents moved me to an all-white city in Corvallis and we were the first Mexican family in that school district. The teachers did not know how to teach us, they were nice teachers but their way to teach us was to ignore us...

-First Generation Transfer Student

Monica's recognition of her desire to learn and help others with similar issues led her back to school. The same social context that stopped her earlier in her life gave her the motivation to earn a college degree in order to help others in similar situations. Monica described how she solidified her career aspiration of working a job where she could help struggling high school students stay in school and eventually transition to college.

When I started going to school and taking classes[in college], I realized I do love school, I do love learning and I started having to think about why I started hating school so much. It wasn't so much that I hated homework, I was embarrassed to read, I did not feel like I was connected to anything, I did not have any mentors or teachers telling me I could do it, or do this, ... I told myself that I would love to be in a position that could help those students. Like doing two different jobs like working in a university setting and kind of mentoring those kids from high school all the way to college...

First Generation Transfer Student- 
Monica connected feelings and issues from her childhood to her current occupational goal. Her own high school experiences acted as a motivation that led Monica to pursue her career goals. Family background helped mold the career aspirations for both Lance, a traditional student, and Monica, a first generation student.

\section{Differences}

While their family backgrounds affected both traditional and first-generation students' occupational aspirations, there were differences in how family background inspired these two groups of students' occupational aspirations.

Theme 2: Family experiences influenced each group's career aspirations in a different way.

Family background led Traditional students to aspire to occupations that where similar to those of their parents. Traditional students' career aspirations led them to seek college degrees that could help secure jobs in the same social class as their parents. On the other hand, family background motivated first generation students to aspire to occupations that were different from those of their parents. First generation students sought college degrees in order to realize careers that would lead to economic stability, or to change the social injustices they experienced as children.

Traditional student's childhood and family experiences led them to aspirations for careers of a similar social class as that of their families

Hanna, a traditional transfer student, reported that she worked in the project management department of a large corporation. Hanna stated that her educational goal was to earn degrees in both engineering and project management. She noted that possessing this 
combination of degrees would qualify her to work as an executive project manager supervising teams of engineers. Hanna discussed influences on her current occupational goals by reflecting on her childhood experiences:

(I was) probably inspired by my dad taking me to see the planetarium at OMSI when I was a kid, we did that quite a few times and then on occasion [we would take a] trip down to Arizona where my family is from. There were two times where we got to sit out and there were meteorite showers, out in Arizona, out in the flats where there is no light. We would pull off to the side (of the road), pull out the blankets, and watch the meteorite showers. And I have been a bit of space nut ever since, so aviation seemed to me to get into that kind of space race kind of thing, probably way back in the way back of mind that was probably were most of the inspiration for going aviation was. I guess my Dad was my inspiration on that...

Traditional Transfer Student-

Hanna made a link between past family experiences and her current career interests. She also explained how her parents helped to strengthen her interest in space aviation and engineering:

... My parents always had fantasy Sci-Fi books and I am an avid reader... I would love to see some of the things come to life, the door open when you walk up to the super market I love seeing it applied to everyday life, the monitor over the bed in Star Trek, they have things like that coming out.

-Traditional Transfer Student

Hanna grew up in a family that encouraged her interest in how science could be applied to everyday life. Her family took her on visits to a science museum, trips to look at the stars, and gave her access to books that allowed her to imagine a world that she could be part of and help to create. Given the social context Hanna grew up in, engineering was a logical career choice for her. Her interactions with science and space did not guarantee a life as an engineer but these experiences provided Hanna with the idea that it might be possible for her to become an engineer. 
First generation student's childhood and family experiences inspired them to careers in a social class that was different from that of their parents.

For Liz her upbringing was a major factor in her going to college and helped form her foundation as to what she wanted to do. Liz had been out of high school for a little over a year working at a retail store it the mall when she chose to try to go to college. When asked about her choice, she explained the reasons behind that decision.

I always wanted to go to college I grew up very poor and [my mom was a] single parent and I saw my mom work full was also a very large factor. To see her work so hard for little money and then see her come home extremely exhausted. That kind of took a toll on me after a while... I saw how hard she worked, for not a whole lot to just provide for us and that was definitely a huge factor in deciding is going to college. I just kind of knew that I wanted to do something more that work full time for not a whole lot of money.

Watching her mom work very hard for low wages was a large influence in Liz's career choice. This influence is reflected in her decision to become a certified public accountant, an economically rewarding career. Liz explained her mom's influence on her choice to be an accountant:

[My mom's] work ethic was very inspiring too; a huge part of accounting is ethics and professionalism, even a big thing they emphasize if even when there is something unethical going in you are supposed to maintain your own ethics I guess you are supposed to hold yourself to a higher level than others, as a professional.

-First generation student

Liz stated that she got her work ethic from watching her mother and related this to her chosen profession of an accountant. Liz's quotes illustrate the influence that family life can have on first- generation students' career aspirations.

Bella, a first generation transfer student, reported that she is returning to college after taking some time off. She wants to work as a college professor and researcher in criminal justice. Bella noted that she developed a strong interest in criminal justice as a 
career choice after experiencing a family tragedy as a child. Additionally, she shared that while she was growing up, the police had to frequently intervene in situations with both her family and neighbors. Bella's personal experiences led her to develop a passionate interest in criminal justice, and a desire to understand the factors involved in how a person becomes a criminal. Bella shared how her family history and growing up around police intervention led to her aspiration for a career in the criminal justice system.

I am one of 21 children neither of my parents have beyond a grade school education, truth of the matter is my father signed an $\mathrm{X}$ for his name, education was always pushed but I felt it could never really be obtained, unfortunately we had a lot of state intervention in my family ..., the police, you name it, it happened. As a young child, I became fascinated with criminal justice and criminology not as much the lock them up throw away the key side of it [but] the path to becoming part of the criminal justice system. Seeing it from the other side of things, so as a child I became fascinated with criminal justice...

First Generation Transfer Student-

Bella reported that her interest in a criminal justice career became even stronger when her sister was murdered.

What truly got me just hooked, when I was a sophomore in high school my sister was murdered, and they found out in 2010 he is a serial killer. So when I was sophomore in high school I wanted to become an attorney after my sister was murdered I wanted to research/ work on, figure this side of it out. What led to this behavior? So my focus kind of changed, it was personal for me. Nothing seems to just hook me like the criminal justice system and criminology in general; no other topic fascinates me like this.

First Generation Transfer Student-

For Bella her career interests were closely ties to childhood experiences. She hopes to turn her to degree into a job within the criminal justice system so she can affect change within that system. This sub-section reviewed the findings from the overarching research question number two. The findings in this sub-section illustrated that family background affected career aspirations for both groups of students. However, traditional and first-generation students differed in how family background influenced 
their career aspirations. Traditional students such as Hanna had family members that influenced her aspirations by introducing her to new possibilities for education and future occupations Bella and Liz's occupational aspirations were shaped through observing their families' struggles; both women aspired to careers so that they would not face the same struggles in their own lives.

Research question 2a: How do students understand how work relates to occupational aspirations?

Research question 2a explores students' understandings of the relationship between work experiences and career aspirations. Work experience influenced the career goals for both first generation and traditional students. However, there was a difference in how each group of students used their work experiences in relation to the formation of their career goals.

\section{Similarities}

Some of the first generation students and many of the traditional students mentioned work as having an effect on their career goals.

Theme 3: Both traditional and first-generation students shared that paid work influenced their career aspirations.

Patt, a traditional community college transfer student, mentioned that her work experiences influenced her career goal. Patt stated she is interested in working in gerontology, specifically with those in the LGBT community. 
When I was working the, retirement community... [I saw] two people, who while not openly out, not out, being tormented and ridiculed by bullies within this community, by residents. Knowing also, many times people in the LGBT community have to go back into the closest to go into a residential or care community [influenced my goals].

Traditional Transfer Student

For Patt, this and other experiences she had at her job inspired her to not only to seek a career in gerontology but also to specialize in working with a specific population.

Monica, a first generation community college transfer student, wanted to work as

an adviser or administrator in academic success programs in a college or high school.

She explained that her work experience influenced her goal.

I want to work with students that either are walking the same road that I walked as a high school [student], that is basically a minority that could not make that transitions form high school to college because of lack of information. I want to be in a position to help them make the transition smoother... When I was at [the community college] I worked at the women's resource center. That allowed me to work with students that were in my shoes, kind of made me feel like I was not alone and these kinds of programs are not in high school and for them to make that first step into college from high school it is the biggest step they are going to make. And once you're in there it is all about whom you know. Unless you go looking for it yourself, you will never know these programs are put there to help you...

My goal is to eventually work in a university in a program such as TRIO or DMSS [student success programs that focus on first generation, low-income students and students of color] being in a position to help others make the transitions. Their college years would be more successful than if they were not in the programs.

First Generation Student-

Monica explained that, while she knew she wanted to help others "like her"; she learned more about which career would allow her to do that by working in the Women's

Resource Center and later in a student success program.

Both Patt, a traditional student, and Monica, a first generation student reported

that work experiences influenced their career goals.

\section{Differences}


While work experiences influenced both first generation and traditional student's career goals, there were differences in the ways in which work experiences influenced these two groups' career choices.

Theme 4: Work experiences influenced each group of students' career aspirations differently.

Work experience provided traditional students with opportunities to learn more about their already chosen careers

June, a traditional transfer student, stated that she aspired to be a clinical social worker.

Her work experience in a social work clinic provided her with the opportunity to explore

possible career options within the field. Through personal initiative at work, June created experiences and opportunities. The following exemplifies this idea:

I have made it happen that way for myself, when I started there I was just answering the phones, it didn't have anything to do with anything, and now I am a little bit more people oriented, in helping people. I have been asking for more roles at work that go in collaboration with that. I helped, starting doing these treatments for patients in the office. I asked if I could become a liaison and help them coordinate their benefits because dealing with insurance companies is like crazy. These treatments are very, very expensive and people come in once every eight weeks and it is $\$ 7000$ every time. I asked the office manager if I could help coordinate that piece of that and work with the patients one- on- one to help them get other resources to help them pay for it, they let me do it...

-Traditional Transfer Student

June learned more about her chosen field by taking the initiative and creating opportunities for herself at her current job. In the process, she also earned valuable experience and possible recommendations from her current employer for her future endeavors in the field once she completes her degree.

Maria, a traditional transfer student, also used her employment history to further her future career goals. Maria has created an education plan that will lead her to a career 
as a counselor and FBI profiler. She explained the connections between her past and current work and her college and career goals:

In Florida, I was an executive assistant for a psychology office for children and then I moved on to being in the hospital in the communications department and they have a psychiatric ward there. Now I am working in a medical facility that also offers mental health service. Basically, in every position I have been looking for a network so I can have a backup plan to go to. Being a counselor in the kid's office, being a counselor in the psych department of the hospital, being a counselor at the clinic, there is always a way I can network and get in for my long-term goals.

Traditional Transfer Student-

For Maria, work is much more than a way to make money, it is a place that provides opportunities to make connections to potentially valuable others. Additionally, Maria shared that her self-confidence comes through in her strategic choices for how she uses her employment. Specifically, she addressed how she utilizes work to build networks that could facilitate her career goals.

Maria - Basically just bonding. I am very open person, and I am very driven when I want something I go for it. I have made it known the past two years at the clinic I have been working for that "hey I want to be a counselor" , "you people need to open up a position for me". So when I get there, I am going, and my plan is to, we have a director for behavior health I am basically going to be her protégé. She is getting close to retiring and its couple of years for her to train me and to eventually take over that role.

Jeff-And they would pay you while they train you?

Maria- Yes I would be a counselor there.

Jeff-They are opening up a position that they do not have now. It was your creation, you got a job with them, and they were interested in hearing your thoughts after you proved yourself?

Maria- Yes, yes, that was welcomed with complete encouragement...I find staying open with my job and letting them know where I am at and not demanding what I want but demanding kind of, making it known this is what I want. I am an excellent employee there and putting things in place now, polices and working so closely with that department and favoring it. I think its s great strategy, its working.

Traditional Transfer Student-

Maria consciously used her work to gain experience and a build a network of supporters and connections that she plans to use to realize her career goals. 
Both June and Maria used the jobs they worked before and while they were in college to strengthen their chances of realizing their career goals upon graduation. Post-major choice work experience provided first generation students ways to explore possible career opportunities.

Jasmine, a first generation transfer student, decided to major in psychology at

PSU. After she transferred, Jasmine found her current job at a research center and

reported using it to learn about possible work positions she might qualify for with a

psychology degree.

Jasmine explained the connection between her current work and career goals:

I work with a regional research institute. They have various programs in that department, they have social work department in that group, and they have psychology department in that group. They work with real clients from various networks; the project I am working with is called [...] and assists foster care youths. They are real foster care youths, pretty much they are helping the youth transition out of foster care. ... I don't work directly with the youths I work with the program, I do administrative work, paper work all that stuff and I have been working there since February of this year. So since I have been working there I have been full time in college too. It is not stressful for me because I am learning some things in that work place and being that it is a social work environment incorporated with psychologists that are conducting research on different kind of projects I ... I think it will benefit me in the future. I might not know how [inaudible], or how soon but it is something I have been keeping my eyes on.

First Generation Transfer Student-

After Jasmine decided to major in psychology at college, she was able to obtain a job in an area that was of interest to her. This job allowed her to explore a possible career options she can pursue with her psychology degree.

Laura, a first generation transfer student, reported she is currently majoring in speech and hearing at PSU. She used her current position as a nursing assistant to observe and discover how being a speech therapist compared with other jobs within the medical field.

I think that, I guess you could see a process of elimination; I knew I did not want to be a nurse after seeing how hard it is and the stress. The nurses deserve a lot of credit. Never want to be a 
physician or a PA [Physician's Assistant] I would never want to be a respiratory therapist because of all the buggers, and they were all very interesting. I think if I could be 18 again and start up fresh I think I could do almost anyone except for the respiratory. But things like a Doctor and even audiology which is kind of part of my major which is on that linear path just seems like a little too much schooling even for how far have come. More than those like 6 years out are still sort of off the table. Occupational therapy and physical therapy looked interesting, very physical and the idea of getting people up and down to the bathroom too, I would get paid more for doing that, I sort of doing a lot of those things now but just that kind of work of over time I think could be difficult on the body. But with speech, it's very... like in the hospital I only saw work with adults and a lot of under neurological aspect. People who had strokes, seizures, and sort of traumatic brain injury and I was just very intrigued by the types of tests and work that they would use with these patients and then how they could just sit down and have nice quite time, conversation with people. Not a lot strenuous activity involved, many patients do not want to move and do not want to get up. While with speech therapy, you do not have to lug them out of bed and another component.

First Generation Student-

Laura's quote illustrates how complex her major and career decisions were. She stated she tried to make her career path decision based on her practical experiences at the hospital where she works. Laura reported that her career choices were influenced by both the various duties connected to different occupations as well as the amount of schooling that she would need to earn the required degrees associated with each occupation.

This sub-section presented the findings for research question 2a. Both traditional and first-generation community college transfer students reported that paid work influenced their career aspirations. However, they differed in how they used their work experience to realize their career goals. Maria and Laura, traditional students, spoke of their current jobs while in school as things they built upon as part of their major to career paths. June and Jasmine, first generation students, reported their work experience while in school s provided them opportunities to explore potential occupational positions associated with the majors they choose after starting college. 
Research Question: 2b: How do students understand how mentoring affects their occupational aspirations?

The final sub-section explores the findings for research question $2 \mathrm{~b}$ : How do students understand how mentoring affects their occupational aspirations.

\section{Similarities}

Two common themes were found in the responses of both traditional and first-generation community college transfer students with regards to how mentoring influenced their career aspirations. First, both groups of students discussed that mentoring influenced their career aspirations. Second, both groups stated that they received mentoring from professors and academic advisers.

Theme 5: Both groups of students acknowledged that mentoring influenced their career aspirations

Jade, a first generation student discussed how her mentor influenced her career goals.

"I am also in the student success program and my adviser up there ... sat down and was, "what do you want to do in the future and what have you done so far and where do you want to go in the future?"”

-First Generation Transfer Student

The advice Jade received from her adviser/mentor assisted her in recognizing where she currently was on her career path and what steps Jade might have to take to realize her career goal.

Rose, a traditional transfer student, received help from two mentors when she developed her career path.

“... the counselors, the authority figures, I [had] meetings [with] put that idea in my mind but [my] friend ... boosted my confidence a little bit , 'you know me and you think I could do it' , I really could do it," 
-Traditional Transfer Student

The encouragement Rose received from her mentors helped her to realize she could achieve her career goal.

Jade and Rose's stories were typical of those of many first generation and traditional. College-based mentors had a powerful influence on students' career aspirations.

Theme 6: Professors and academic advisers mentored first generation and traditional students

Rose, a traditional transfer student, reported that she received mentoring from a professor.

I have great professor ... she was amazing... I took her for human sexuality and took her for ... I do not remember the other one adolescent, and she was just fantastic... [She] was willing to sit down and [we] talked about [the] future and stuff like that. -Traditional Transfer Student

Rose stated that talking to this professor about the future and being in her class influenced Rose to major in psychology. Once she became a psychology major, Rose shifted her career aspirations to jobs in that field.

An academic adviser introduced Maria, a traditional student, to forensic psychology. Maria explained that with the help of her adviser and her own personal research she made a career choice.

I meet with my advisers regularly about every two weeks, just to make sure I am staying on track. Then one of my advisers had me take the test where it is the introverted, extroverted, judgmental, and non-judgmental. I scored very high on the criminal justice side of it, she threw it out there as a suggestion, and I am good at science as well. [In addition,] I just latched onto the idea after doing more research.

-Traditional Transfer Student 
Maria's mentor guided her to take an occupational interest assessment test; the results of the test led Maria to her current career path

Monica, a first generation student, spoke of how important the mentors she has had while at college were.

“I think for me I cannot stress enough how much programs like TRIO and the [Women's Resource Center] WRC are so important for women like me."

-First Generation Transfer Student

Monica reported that her program advisers provided her with advice and support for her career goals.

Anne, a first-generation student, also received career advice from two mentors, her advisor, and a professor.

"Just got done talking to my adviser and Deanna one of the Associate professors at UP, both have really been able to solidify what it looks like to go to graduate school."

-First Generation Transfer Student

For Anne the next step on her career path is graduate school. The advice she received from her adviser and professor helped her continue toward her occupational goal.

\section{Differences}

One theme of difference was that, in addition to college-based mentoring they shared with first generations students, traditional students received mentoring from two other sources. A second theme of difference was that mentors influenced traditional and firstgeneration students' career choices differently.

While both first generation and traditional students mentioned that mentors influenced their occupational choices, there were still differences in their mentoring 
experiences. One difference between the two groups of students had to do with the additional sources of mentoring that traditional students mentioned. A second difference had to do with how each group of students understood the kind of mentoring instruction they received.

First- generation and traditional students all received mentoring from academic advisers, advisers in programs or professors. These mentors gave students advice about how specific majors related to students' areas of occupational interest. However, traditional students also received life advice and general encouragement from family and/ or employer mentors.

Theme 7: Traditional students received additional support from parent and employer mentors.

Lance, a traditional transfer student, reported he is very self-directed and has a very good idea about the area he wants to work in. When asked about mentors Lance stressed his dad's importance in his life.

\footnotetext{
My dad has only been a driving factor in my life; he is a very charismatic figure that has done a lot for the world. He has been to 56 different countries he has worked for the United Nations he is an incredibly powerful charismatic human being. He has been incredibly motivating for me. He is a really good dad has always been there when I needed him.

Traditional Transfer Student-
}

Lance stressed that his father has been a motivating factor for him. Lance served in the military and expressed a strong desire to have a career serving his country by continuing to work for the government now that his service is complete. Lance stated that he could always turn to his dad when he needed advice. 
Maria, a traditional transfer student, noted that she is currently working toward completing a bachelor's degree in psychology. She explained that plan is to complete her undergraduate program and then earn a Master's Degree in counseling in order to qualify for the FBI profiler-training program. Similarly to Lance, Maria shared how her father's advice based on his own college experiences helps her stay on her career path..

Maria- ... when I get stuck or feel overwhelmed my dad's the first person that I go to for my education needs. Because he did it too and his thing was he always had a child, he had one extra issue. I always go to him and I am like I am kind of stuck what should I do or I am like I am tired of doing my homework on the train Dad and he will look at me like, shut up I've done it, you will be fine, so yea, definitely my dad.

Traditional Transfer Student-

Maria stated that her dad has a several graduate degrees and is the person she looks to for help when she "gets stuck". Her comment regarding how her dad supported her on her school to career path illustrates the power that having a parent with college degree can have for traditional students.

Hanna, a traditional student, shared how an employer provided her with encouragement in regards to her career aspirations.

I had [a manager] when I was working at an electric testing company and another electrical testing company. One saw that, I was secretary / technical writer at the time, had a lot of interest in going back in the back and taking care of some of the equipment. He assigned me the calibrations setups and things like that because he saw I wanted be a little more involved. He was good about $t$ seeing 'oh you do want to do this, you're smart enough to do it lets go ahead and get you going in it.'

-Traditional Transfer Student

While Hanna did not initially have the proper credentials for the job she aspired to, her employer gave her chance to work in the same area of the company as the position she hoped to one day attain. Her manager-mentor encouraged her career aspirations by allowing her to work with equipment associated with the career she aspired to. 
Lance and Maria received mentorship from their fathers. Their family mentors provided Lance and Maria with encouragement to stay on his career paths. Hanna's employer-mentor encouraged her and gave her work opportunities that aligned with her career aspirations. All three of these students' mentors provided them with encouragement that helped these traditional students stay on their career paths.

Theme 8: Traditional and first-generation students valued different types of advice from mentors

Traditional students valued family and employer -based mentoring that offered "life advice" and helped to keep them on track and encourage them to continue on their career paths.

Lance, a traditional transfer student, received "life advice" from his father.

[My Dad] always talks and tries his best to give any advice he can and he gives really good life advice. So doesn't matter what I would have done but he would always be a good mentor, always helpful

Jeff- would I be correct in saying many of your mentors have been more on an individual level, helping you on an individual. Not particularly a specific choice but helping you be a better human being helped you make those choices

Lance-Yea, the rest is just bureaucracy.

Traditional Transfer Student-

The previous quote illustrated the importance of his dad's "life advice" for Lance. For Lance, his dad's mentorship helped him to live a better life. He stated that the advice he has gotten from his dad has been general life advice and that "the rest is just bureaucracy". His family mentor's advice has been important in Lance's personal development and in how he makes life choices, such as career decisions June, a traditional transfer student, also received encouragement from her mentor that helped guide her choice of career. 
I have a therapist and we did a lot of talking about that. I had quit my job and I was taking some classes and I was “I don't know what I am going” we did a lot of talking about what I liked about the jobs I had and what I didn't like about jobs I had and kind a found things and social work made sense. As a retail manager a lot of what I did was, manage problems. that part of my job I liked a lot. It was dealing with the business and customers that I did not like... the therapist she is a social worker, she kind of, at this point, a life coach, mentor. It was that whole visualizing myself and doing what she is doing and sitting there and thinking could I do what she is doing right now, and I could totally do this with other people. Other than the fact I have to pay her, she is really great

-Traditional Transfer Student

Both Lance and June stated that their mentors provided them with "life advice" and guidance that helped them with their career choice.

First generation students often stressed the direct link between the advice they received from their mentor's and their career choice.

In contrast to how mentors provided life advice for traditional students, first generation students' mentors influenced students' career aspiration by providing them with information that directly related to their career goals.

Bella, a first generation transfer student, remarked about how she met a professor who was the first African American woman to work in the county sheriff's office and that this professor became an important mentor for her. Being African American herself, Bella explained that this was a very important contact.

Bella described the type of advice she received:

I had a heart to heart with her and she encouraged me. [She] gave me a print out, of women of color working in the field. They are police officers they are ... [she told me] talk with these women before you make a permanent decision. I went and talked to about eight different women of color in the field, officer of neighborhood involvement, Portland Police, people she knew. Every single women of color said it is hard, prepare to deal with some of the craziest crap you have very imagined as a black women but would [that they would] not trade it for any other career in the world. That was the piece I needed to hear; 'would not change a things.'

First Generation Transfer Student- 
Her mentor provided Bella with information about the general field of study she was pursuing rather than specific pathways to jobs in that field. This professor mentor also introduced Bella to other women in the field who helped familiar her with the occupational environment she would face if she worked in this field.

She took me under her wing connected me with people, particular women of color in the field that was able to give me, not the poster child version but, here's the real deal, you are going to be dealing with crap, you are going to dealing with a ton of crap. But you are going to be loving what you are doing so much that it will be worth is. That's what helped me make my final decisions, interesting women that have been her for 5, 10, 20 years. Oh saying you are going to cry honey but you are still going to get up and go to work the next morning. You are not going to be able to help yourself. So that was important, and she was the key to that.

First Generation Transfer Student-

Bella's comments illustrated how important it was for first generation students to have mentors who have career relevant experience that they can share with students who are choosing their career paths. The stories and advice Bella's mentor shared with her she strongly affected her future career decisions.

Jasmine, a first generation transfer student, stated that while initially she was excited to transfer to the university, she also was aware that her parents could not really help her with choosing a career. Jasmine indicated that she was very anxious about her career choice and did not want to have to return to college later in life because she had made a wrong choice. After she arrived at the university, she got into a first generation student support program much like the one she was in at the community college. She explained that her new adviser mentor spoke to her about various careers she could do with a psychology degree and helped her better understand her career options.

[My adviser] pretty much helped me to decide to do the general psychology, because she was hearing hesitation from me like 'oh I like the human resource'... She opened my eyes that people with psychology, can get a career in HR and I do not necessarily have to have a business degree but since I was being hesitant, I was not really sure if I wanted to [inaudible]. Since I have other interests, you know to work in the counseling department or mental health department. 
Jasmine's mentor helped her solidify her major choice and tie that choice to possible career outcomes. Jasmine now is a psychology major and plans to graduate from the university within the year.

This section illustrated that mentors provided traditional students, Lance and Maria, with life advice that helped them stay on their career paths. Mentor helped first generation students Bella and Jasmine, figure out and clarify their occupational goals. This help came in the form of domain specific information that assisted first generation students in developing paths to reach their career goals.

\section{Summary for Research Question 2}

Research question two explored how traditional and first-generation students understand their career aspirations. Family background affected both traditional and first-generation students' career aspirations. However, it is clear that there was a difference in the how family background influenced each group of students' aspirations. Traditional students' family background inspired them to aspire to similar occupations as those their parents held. First generation students' family background led them to aspire to occupations that were different from those of their parents. Theme three from research question $2 \mathrm{a}$ pointed out that paid work influenced career goals for both groups of students. However, the two groups of students' used their work experiences differently. Traditional students used their pre-college and current work experiences to strengthen their chances at realizing their career goals. In contrast, first generation used their post-major choice work experiences to explore possible occupational positions. Research question $2 \mathrm{~b}$ examined the influence mentoring had on students' career aspirations. Both traditional 
and first-generation students reported that they benefited from mentoring in regards to their career choices. However, in a pattern similar to the one found in research question $2 \mathrm{a}$, the two groups of students differed in who their mentors were as well as the type of advice the students valued. Traditional students reported having two types of mentors. Similar to first generation students, traditional students acknowledged receiving career information from professors and academic advisers. In addition, traditional students' also had access to family or employer mentors. These additional mentors offered "life advice" that helped to keep traditional students on track and encouraged them to continue on their career path. First-generation student's' mentors were often program advisers, academic advisers or professors. These college-based mentors provided first generation students with information about career choices that helped these students with their career aspirations.

Research Question: 3: How do students understand the connection between their choice of major and career aspirations?

Research question 3 explored students' understandings of the link between their major choices and career aspirations. 
Figure 3: Similarities and differences of findings for research question three

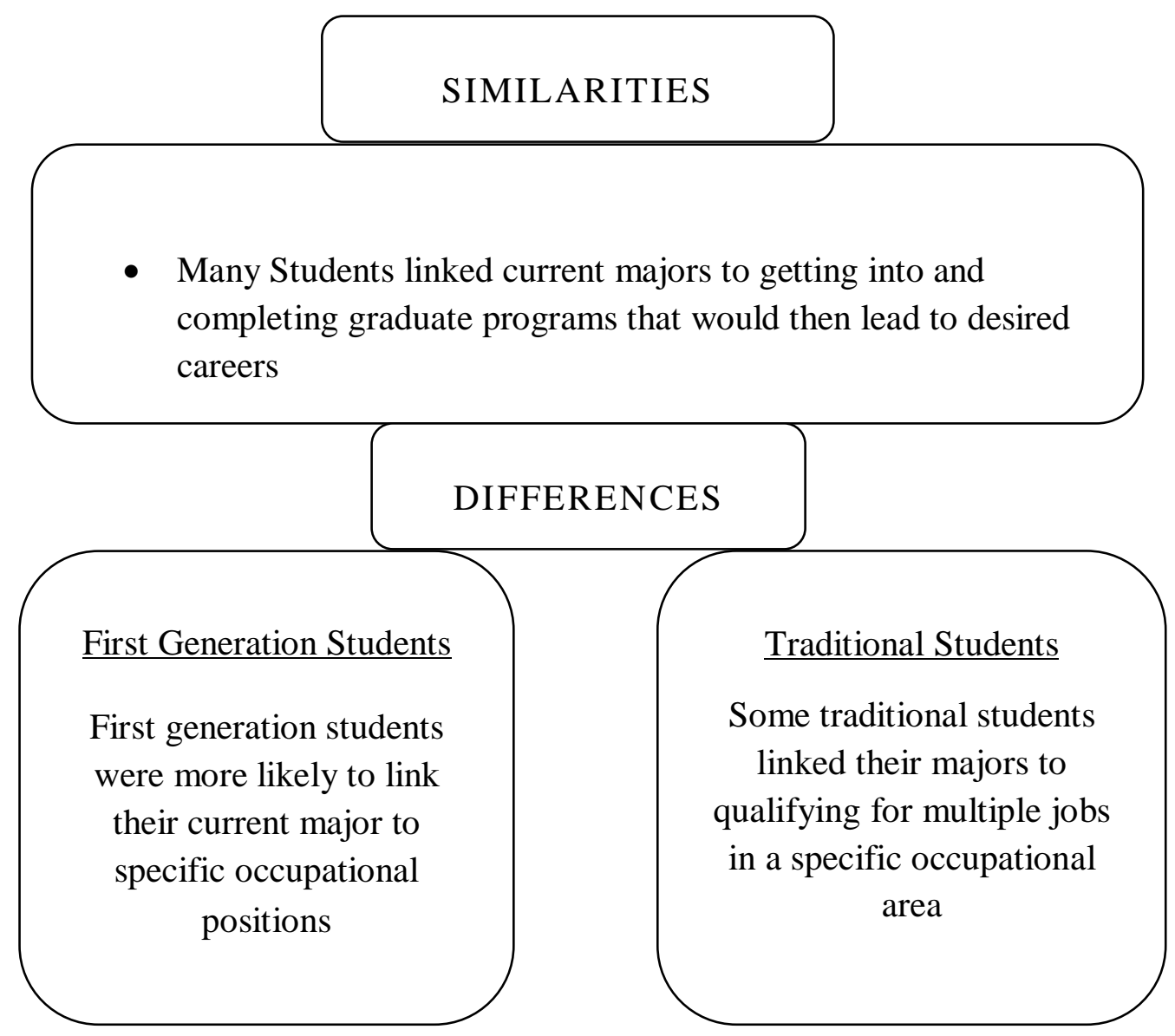




\section{Similarities}

Many of the traditional and first generations community college transfer students in this study viewed their major as the first step in their career plan. Their second step linked their major choice to getting into and completing a graduate program that would qualify them for their career goal. Table \# 2 describes what types of graduate programs students planned to apply to after completing their undergraduate degree.

Table 2 Type of Graduate Program by Student Group

\begin{tabular}{|c|c|}
\hline Name & Type of Graduate Program \\
\hline \multicolumn{2}{|l|}{ First Generation Student } \\
\hline Jasmine & Master's in Counseling or Social Work \\
\hline Christa & Masters of Science in Counseling \\
\hline Tera & Master's Degree in Public Health Administrator \\
\hline Anne & $\mathrm{PhD}$ in Sociology \\
\hline Bella & PhD in Criminology \\
\hline Laura & Master's Degree in Speech and Hearing \\
\hline Monica & $\begin{array}{l}\text { PACE (Postsecondary Adult and Continuing } \\
\text { Education Master's Program }\end{array}$ \\
\hline $\mathrm{Liz}$ & Certified Accountant \\
\hline Martin & Master's Degree Engineering \\
\hline Jade & Pharmacy or Medical Doctor \\
\hline \multicolumn{2}{|l|}{ Traditional Students } \\
\hline Maria & Master's in Counseling \\
\hline June & Master's in Social Work \\
\hline Cyndi & PhD in Sociology \\
\hline Rose & Master's in Social Work \\
\hline
\end{tabular}


Theme 1: Many students linked current majors to getting into and completing graduate programs that would then lead to desired careers.

A common theme for both first generation and traditional student participants was that they linked their current choice of major to getting into and completing graduate programs as the next steps in their career plan.

Maria, a traditional transfer student, linked her psychology major with getting into getting a Psychological Counseling master's program and eventually a position as a counselor with her current employer. When asked about her next step after completing her Bachelor's degree she stated:

I will be done with my bachelors in two more terms. I am actually taking a year off from working and I am going to go straight into graduate school and hopeful finish in a year to a year and a half. I have networked and formed bonds with my company. My company works for the low income and homeless population, which is the heart of what I want to do. I am guaranteed a position as a counselor there as soon as I finish my master's degree.

-Traditional Transfer Student

Maria linked her current major to getting into a master's program. She stated that successfully completing that graduate program would earn her the degree that will qualify her for her career goal of becoming a counselor. She explained that getting a bachelor's degree in psychology, then earning a master degree in psychological counseling, and next securing a job as a counselor were only parts of her larger career plan.

Maria-Right now it is just to get through school then go to the position as a counselor and begin the steps to be a FBI profiler

Jeff- The FBI is what you want to do eventually?

Maria-I want to do both

Jeff-So you would have your own practice or work for another company, like a consultant?

Maria- Pretty much that would give me a leeway to form a solid schedule to become a counselor...the FBI gives you profiling classes before you even go out into the field. You kind of 
have a foundation that you can build off of, you could build a profile for like a serial killer and they know what they are looking for. Instead of being so disorganized, it is more of a clear-cut version 'go after this guy.'

Jeff- So a master's degree in [psychological counseling] and then FBI profiler classes

Maria-Right

-Traditional Transfer Student

Maria has linked her education plan, current major, and choice of graduate program, with her career goal.

Laura, a first generation student, noted that she also plans to attend graduate school as the next step in her career plan. Laura linked her current major to getting into a communication studies graduate program. She explained that completing a degree in that program would qualify her for speech and language pathologist positions. Laura stated that she currently works as a nursing assistant at a local hospital.

Laura- My plan is to get into graduate school for next year and continue to work at [Hospital X]. Which I am currently doing and complete my schooling and get a job with [Hospital X or its sister hospital] in speech pathology. So that's the plan and I can deviate from the plan, I feel comfortable if am not with [Hospital X] my whole life

Jeff- Go somewhere else, degree is usable in just about every hospital I assume?

L- Oh yea, like rehab and the schools and a lot of wherever it is.

Jeff-Would you consider that your ultimate career goal is to be a speech...

L- yea, a Speech Language Pathologist.

-First Generation Transfer Student

Laura and Maria both linked their current majors to getting into and completing specific graduate programs. Completing their respective graduate programs would provide them with degrees that would then qualify Laura and Maria for the careers they wish to have. 


\section{Differences}

Theme 2: Traditional and first generation differed in how they linked completing their degree with their career goals.

Some traditional students linked their majors to qualifying for multiple jobs in a specific occupational area

Traditional students commonly articulated that earning a degree in their major allowed them to qualify for several different jobs within an occupational area.

For example, Ken, a traditional student, described how earning his bachelor's

degree in criminal justice would prepare him for doing several different jobs in the area of criminal justice.

Jeff-When you came back to school, you said your intention was the criminal justice degree. What is your next step after you graduate?

Ken-Hard to say, my wife, her work, she is the big bread winner, there is a possibility that we may be re-locating, it's hard to say I know that a lot of the, I don't intend to be a law enforcement officer or correction officer however, parole, probation, fraud investigator some of those other avenues . I just, maybe it was a naive assumption, but I am kind of the assumption that those types of jobs are available in most metropolitan areas. The opportunities for that as opposed to something really specialized would be there.

Jeff- So you are thinking of parole?

Ken -Possibly, I have done government work with the military, I have seen the bureaucracy that goes with that, and I am not enamored with it by any means. I know there is some bureaucracy in the corporate would and it is different. I am pretty flexible from what I have done in the military. I know that the parole and probation avenue is manageable by me without too much difficulty. Fraud investigator, some of those other investigator, or compliance type, inspectors and things like that, again those are not new roles for me, its maybe kind of not shifting direction but shifting the job skills to civilian of corporate America.

-Traditional Transfer Student

Ken shared that he has work experience from both his military and civilian careers that he draws from when figuring out his career options. He noted that he believes his range of experience, along with his degree in criminal justice, will qualify him for several specific jobs in the occupational area of corrections and criminal justice. 
Lance is a traditional transfer student majoring in political science. Lance linked completing a degree in his major to several different jobs within the same occupational area. Lance discussed the link between completing a degree in his major and his career plans.

[The] political science degree is something very general that could help you get into that field. They don't really care what your degree is in, normally, as long as you have degree, and political science is relevant to that area anyways so that's why I picked it...Political science ... is just an ends to a means or a means to an end.

-Traditional Transfer Student

When asked about the next steps on his career path, Lance mentioned he was currently completing an internship that he hoped could serve as a bridge between completing his bachelor's degree and his career goals. Lance stated:

I am already working on that I have an internship; I mean work-study at the VA downtown that does the benefits for veterans. I am setting that up to get a government job, my goal is by winter term to have an set up an account on us.govermentjobs.org and be applying to government jobs before I graduate., I am looking at what the central intelligence agency wants [as well as] what the defense agency wants . I am going to apply to them. I am going to apply to homeland security jobs. TSA is like my back up to work doing something; you know management, middle management in the TSA then VA or whomever I get a government job working with.

-Traditional Transfer Student

Lance linked his major to several different positions within a larger occupational area.

Craig, a traditional transfer student, stated that he would be graduating this year

with a degree in sociology. He linked his degree in sociology to multiple occupational positions.

Jeff- You have [had] several different paths you were looking at, what career opportunities you think are available to Sociology

Craig-By the time I landed on Sociology I wasn't as worried about finding a career, it's a an interesting field for me to study and I will have a degree when it's done. I left the military but I still want to do something in public service, city state something and any degree can get a state job My mom had a dual degree Psych, Soc and she used to work for the state when I was a kid. I know can get a job.

Jeff-So with the bachelor's degree and military service you feel you have what you need. 
Craig-Yea,

-Traditional Transfer Student

Craig noted that his mother had a degree in sociology and she was able to get a job within the state government. The knowledge that his mother found employment with the same degree he was earning gave him confidence. Additionally, Craig stated that he believes his military experience will help him get a job.

Ken, Lance, and Craig all linked completing their respective degrees to qualifying for several different jobs within different occupational areas.

First generation students were more likely to link their current majors to specific occupational positions

Nearly all of the first generation students linked their major to a specific occupational position. While a few traditional students expressed a similar approach, the majority of first generation students used the strategy of directly linking their majors to jobs.

Liz, a first generation transfer student, shared that she is getting close to completing an accounting degree. Liz stated a direct connection between her current major and her career plan.

Liz-I really want to work public accounting that is very hard. [Certified Public Accountant, CPA]. [I] would be doing accounting for a large corporation or auditing a large corporation doing taxes for a public company. My goal is] to actually do professional accounting. The way it goes in a public firm, it staff accountant, manager, senior manager and then eventually the goal so to become partner, I guess that would be an ultimate goal but that is a very hard goal to achieve obviously.

-First Generation Student

Liz has directly connected completing a degree in her major to an immediate job as a CPA and a longer-term occupational goal of eventually becoming a partner in an accounting firm. 
Christa, another first generation student, stated that she would be graduating with a bachelor's degree in psychology. She has linked her degree to her career goal of working as a forensic psychologist. She also linked her degree to a specific job, working for the state as a forensic psychologist, she wants to pursue as another step in her path to her ultimate goal of having her own practice.

I actually want to work for the state for a couple of reasons. [First] to be a forensics psychologist you need connections with judges and lawyers in the legal sense of it. [Also] I want to work for the state for the ten years to [qualify for the loan forgiveness program] and then my ultimate goal is to open up my own practice as a forensic psychologist.

-First Generation Student

She has linked her degree to a specific occupation, forensic psychologist. She stated she is also aware of an intermediate job she will need to have before she can achieve her ultimate goal having her own practice as a forensic psychologist.

Martin, a first generation student majoring in engineering, explained that he is interested in a job as a power systems engineer. He has linked his degree to a specific job in the area of electrical engineering.

I found the proper term for the kind of job that I want, power systems engineering, which is a subset of electrical engineering. It is a distinction made in other countries. That there is electrical engineering and electronic engineering, In America they are both called electrical engineering

-First Generation Student

Martin stated that he would need a graduate degree to qualify for the specific job he wants. He has linked his undergraduate major to graduate degree that will qualify him for his desired career.

Liz, Christa, and Martin are examples of how first generation students linked completing degrees in their current majors to specific occupational positions. This theme dominated first generation students' narratives. 
Summary for research question 3

Research question three explored how students understood the link between their choices of majors and their career aspirations. Two themes emerged. Theme one, showed that many traditional and first-generation students linked their majors to applying to graduate programs as the next step toward their career goals. Theme two showed that there are differences in the ways that traditional and first generation students linked completing their degree with their career goals. Traditional students linked earning a degree in their chosen major to qualifying for multiple jobs in an occupational area. In contrast, a majority of first generation students indicated that they linked their major with specific occupational positions.

This chapter discussed the findings for the three research questions of this research; how do students understand their choice of major? how do students understand their career aspirations?, and how do students understand the connection between choice of major and career aspirations? The next chapter will review the key findings and new understandings. In addition, the findings will be discussed in relation to the literature as well as examined through the lens of the theoretical framework used for this study. 


\section{CHAPTER FIVE: DISCUSSION}

This chapter is organized into three sections. First, key findings and new understandings will be discussed. Second, the relevance of the findings will be demonstrated by revisiting the literature. Finally, the findings will be examined through the lens of the theoretical framework used in this study to present a "big picture" story of how differences in the ways first generation and traditional community college transfer students choose college majors and link majors to desired careers affect career outcomes and whether completing college leads to social mobility or social reproduction.

\section{Review of Findings}

In this thesis, I explored three large questions. The first big question asked; how do students understand their choice of major? I found that a majority of both first generation and traditional community college transfer students did not change their major after transferring to the university. Additionally, both groups of students linked their major choice to positive experiences in classes. However, there were differences between the two groups of students concerning how mentoring impacted students' choices of majors. I found that mentors helped first generation students create class schedules that allowed these students to efficiently complete degrees in their majors. Mentoring also validated first generation students' beliefs that they had the abilities needed to complete advanced course work. In contrast, mentoring did not influence traditional students' major choices. 
The second big question asked; how do students understand their career aspirations? I found that family background affected both groups of students' career choices. Traditional students were inspired by family experiences to reproduce their families' history. Examples of traditional student's parents' jobs included engineer, social worker, and government worker. Traditional students aspired to careers that were on the same class levels as those of their parents, and in several cases actually aspired to similar careers as their parents.

In contrast, first generation students' family backgrounds inspired these students to aspire to careers at a higher social class level than their parents. Examples of parents of first generation students' jobs included courtroom clerk, hospitality industry worker, and house cleaner. First generation students did not want to duplicate their parents' occupations and in some cases, these students aspired to careers that would let them help others overcome the barriers the students experienced in their childhoods. I also found that work experience influenced career goals for both groups of students but each group differed on how these experiences were used. Traditional students used their past and current work experiences to help them better their chances at realizing their career goals by networking and gaining more experience. First generation students used their current work to help them explore different occupational positions. Additionally, I found that mentors provided both groups of students with valuable career path information. While college advisers and professors mentored both groups of students, traditional students received additional mentoring in the form of "life advice" from their families and employers. 
The third question asked; how do students understand the connections between choice of major and career aspirations? I found that some traditional and almost all firstgeneration students linked completing their undergraduate degrees to getting into graduate programs that would give them the credentials needed to realize career goals. However, a major difference between the two groups of students was that traditional students linked their majors to multiple jobs in an occupational area while first generation students linked their major to specific occupational positions.

Connecting findings to existing literature

In the following section, I will discuss the major findings for each research question with relevant literature.

Research Question 1: How do students understand their choice of major?

Research question one focused on how students understand their choice of major. Within the literature, past studies have linked major choice to gender or social economic status as major influences, (Leppel, Williams \& Waldauer 2001; Ma, 2009; Montgomery 2007; Aries \& Seider 2007). While different studies used various measures of social economic status, my study emphasizes the link between education-based SES and major choice.

Choosing a major is part of the process of earning a college degree. In the literature, researchers have made connections between major choice and occupational pay (Cebula and Lopes 1982; Montmarquette, Cannings, and Mahseredjian 2002). These studies looked at how much value students place on the extrinsic and intrinsic rewards of the occupation tied to the major. This type of reasoning in choosing a major placed an 
emphasis on rational choice. While choosing a major based on economic outcomes is a part of the reasoning behind the choices made by the students in this study, my findings suggest several additional influences, both in and out of the academic environment, are also important influences on students 'major choice decisions.

The students in this study shared stories of exploring various majors before they transferred to a four-year university. After transferring to the university, a majority of the students interviewed did not change their major. This finding indicates both traditional and first-generation community college transfer students' major choice decisions are influenced by an additional factor, i.e. the way higher education is organized. These students transferred from community colleges to the university as juniors. Regardless of where they begin their college careers, by their junior years students are expected to have chosen a major in order to complete their degrees in a timely manner. Most students in this study stated that taking classes in a specific academic discipline, at both the university and their community colleges influenced their major choices. Collegiate coursework both introduced them to a discipline and strengthened their interest in pursuing a degree in that discipline. However, once students were at the mid-point of their undergraduate academic careers, the expectations that all juniors would have settled on a major and the need to complete major requirements by taking advanced courses in those disciplines resulted in a solidifying of their major choices. They had too much invested in pursuing a particular major to consider changing in the same ways they might have during their first two years at the community college.

In this study, first generation and traditional students differed in how their paid work experiences influenced their choice of major. For example, Ken, a traditional 
student, stated that his work experience in military intelligence influenced his major in criminal justice. Another example of how work influenced traditional students' major choice can be seen in the case of Hanna. Her major linked to her current job and in fact dictated her major. By earning a degree in project management and engineering, she is able to receive a higher rate of pay as well as have more opportunities for promotion. In contrast, first generation students spoke of their work experience as a way to "pay their bills" and did not have a connection to their major. For example, Jade works for a retail shoe store and Anne works at a local coffee shop. Each of these students stated that their job was a "pay check" only. One explanation as to why work experiences influenced major choice for traditional students is that their jobs were not entry-level jobs and offered some degree of occupation mobility with a degree. Therefore, pursuing degrees that were connected to their current work was a way for many traditional students to advance from their current job to a more desirable position in the same occupational area. First generation students envisioned that completing their college degrees would qualify them for careers they could not access without those credentials. Therefore, it is not surprising that they saw current jobs as wage-generating placeholders rather than places within an occupational area they could improve upon with additional educational credentials.

Johnson and Mortimer (2011) suggested that extrinsic rewards have a significant effect on major choice for low-income students and less of an effect for higher SES students. It is difficult to surmise if these data indicate an influence of extrinsic rewards on traditional student's major choice. However, in this study, for the traditional students interviewed whose work experience influenced their major choice, earning a degree was 
linked to gaining better pay and/or better employment opportunities. This does not mean that intrinsic rewards were not important, or even that extrinsic rewards were more important for traditional students. Two conclusions can be made from these findings. First, traditional students that spoke of work being an influence on their major choice already were employed within an occupational area where other more desirable positions were available for those with four-year degrees; when these students completed their college degrees in appropriate majors they were on track to attain these desirable positions thereby reinforcing their social class position. Second, first generation students did not work in jobs in occupational areas that offered opportunities for social mobility for those who completed four-year degrees. It is possible that such opportunities actually existed within those occupational areas, but the first generation students in this study were not aware of them.

Another finding of this research was that mentors had effects on first generation students' but not on traditional students' major choices. Many of the first generation students in this study indicated that they worked with their advisers/mentors to create realistic class schedules that let them complete major-required classes "on time" without taking unnecessary, extra classes. Additionally, professor and adviser mentors connected students to key campus support staff - e.g. tutors, financial aid officers -- who in turn gave these students knowledge about how to address specific college-related issues. For example, both Jade and Jasmine used their mentor/advisers to help them create a class schedule that aligned with their major and future plans. Additionally, students mentioned receiving mentoring that gave them vital information in areas such as how to navigate the university system, what groups to be part of, how to improve one's academic skills, and 
how to make a good course plan. These are examples of how mentoring can help firstgeneration community college transfer students adjust to a four-year university. Some students lack academic skills and have lower levels of confidence (Terenzini et al. 1994; Townsend and Wilson 2006) . Helping a student succeed academically falls into the aspect of mentoring that Nora and Crisp $(2007,2009)$ considered to be "academic and subject knowledge support." First generation students in this study often mentioned how important the advice they received from their mentor/advisers was in their success.

In addition to receiving advice and information, many of the first generation students spoke of gaining self-confidence from their interactions with faculty and adviser mentors. Helping to raise a student's confidence is part of the aspect of mentoring Nora and Crisp $(2007,2009)$ describe as "psychological and emotional support." For example, Monica experienced an increase in her self-confidence and desire to finish her degree due in no small part to the support she received from the federal TRIO program that serves first-generation students. One important finding of this research is that, through contact with influential faculty and adviser mentors, first-generation community college transfer students acquired the needed cultural and social capital that helped them succeed in college. Furthermore, this success allowed first generation students to develop the confidence in their abilities to succeed at the university that many traditional students had prior to transferring to PSU. Past research has proposed that transfer students are anxious about whether they possess the academic skills needed to do well at the university regardless of whether or not they actually lack these skills (Terenzini et al. 1994; Townsend and Wilson 2006). I argue that the types of mentoring that the first generation students in this study received helped to counteract their feelings of anxiety 
concerning possible deficits in academic skills. Furthermore, the assistance these students received from their mentors was an intricate part of their persistence and success in their chosen major.

Traditional students did not mention mentoring as an influence on their major choices. When asked about whether he needed advice from a mentor regarding making his major choice decision, Lance, a traditional student, referred to major choice as just part of the college "bureaucracy." In other words, a major choice was something you had to do but did not require assistance. It can be difficult to analyze what was not said about a subject. Still making their major choice decisions did not hold the same cognitive significance for traditional students that it did for first generation students.

\section{Research Question 2: How do students understand their career aspirations?}

Research question two focuses on how students understand their career aspirations. Some traditional and first-generation students stated that family background influenced their career choice. However, the influence of family background was different for these two groups of students. Traditional students' family background motivated them to aspire to careers at the same level of social class as their parents. In contrast, many first generation students were motivated by their family background to create career paths that were linked to higher SES levels than those of their parents. Luttrel (1996) argues that students 'aspirations can be formed based, in part, on what one sees the dominant class achieving juxtaposed with the reality of what one's peers and family achieve. These findings suggest that first generation students resisted what they saw in their potential 
reality based on their parents' social class levels, and attempted to create aspirations more similar to those of dominant class students.

Traditional students expressed that their parents had introduced them to career ideas as they were growing up. Traditional students' experiences such as going to science museums, reading one of their parent's college textbooks or experiencing their parents earn advance degrees all assisted in the creation of their career aspirations. For example, Craig mentions reading through his mother's psychology textbooks. Similarly, Hanna states she read books as a child that inspired her to want to learn more about aviation and engineering. These findings illustrate Lareau's (2003) concept of concerted cultivation ${ }^{9}$. This concept refers to how children from middle class families were raised to interact with the social world. Lareau (20031) argues that middle class children are introduced to intellectual activities and material that cultivate the continuation of their class position.

In contrast, first generation students were often motivated to aspire to an occupation that was different from that of their parents or to change the social injustices they became familiar with as a child. For example, Liz stated how seeing her mom work long and hard hours and come home completely exhausted influenced her in her career path choices. Bella's narrative also illustrates this point. Bella was motivated to go into criminal justice after experiencing local police and social services' interventions in her life as a child. In addition, Bella's career aspirations were also influenced by the murder of her sister. The findings from my study confirm the results of Aries and Seider (2007)

\footnotetext{
${ }^{9}$ Concerted cultivation encompasses the organized activities, conversations and other experiences that that middle class families provide their children. The outcome is to provide their children with a sense of entitlement that helps them navigate institutions and have a feeling on privilege (Lareau 2003).
} 
research, which found students from higher SES tended to choose careers that were on par with their parents' SES and lower income students, would often choose careers that were slightly above their parents' SES. These findings also illustrate that the childhood experiences can have great effects on students' aspirations. It would be a mistake to automatically relegate a student to a specific occupational track based on solely their SES. My findings illustrate that students' SES background experiences can influence them to either resist or comply with the social class scripts, of which they were raised.

This study explored the impact of mentoring on students' career choices. My data showed that traditional and first-generation students both benefited from mentoring in regards to their career choices. Additionally, these findings showed that students differed in who their mentors were as well as the type of advice the students valued.

Both groups of students reported receiving mentoring from academic advisers and professors. However, traditional students also had mentors that were often family members or employers. For example, Lance mentions his father as always being there and giving great "life advice." Another example is Maria, who looks up to her father who has several graduate degrees and she jokes that she has to keep up with her father and "maybe get one more [degree] than him." For first-generation students, mentors were program advisers, academic advisers or professors and these mentors provided information about career choices that helped these students with their career aspirations. For example, Bella had contact with professors who were able to give advice about career paths and strategies to succeed in her career goal. Jasmine received advice from her adviser, who helped her to formulate a career plan. 
Crisp and Cruz (2007, 2009) discusses two aspects of mentoring that apply to these findings: "specification of a role model and support for setting goals and choosing a career path." Specification of a role model describes the mentoring that traditional students received from their parents and employers. This type of mentoring is also similar to what Miller (2002), as cited in Crisp and Cruz (2009) discusses as "counseling [that] involved listening, identifying problems, and encouraging" (537). Both groups received support in setting their goals and choosing a career path.

The main difference between how mentoring affected traditional and firstgeneration students is who their mentors were. Traditional students received the same within-college mentoring from professors and advisers that first-generation students received. In addition, traditional students received additional mentoring from family members who had real life experiences with higher education and often in the same field the student was interested in. Because these mentors were family members, the mentors had strong relationships with these students that had developed over time. This reflects the informal type of mentoring Campbell and Campbell describe that is built up over a period of time (1997 cited in Crisp and Cruz 2009). Additionally, one advantage to a student having this type of informal mentor is that the mentor/mentee relationship can concentrate on long-term goals. This also suggests that traditional students have had more time to create their career plans with their mentors, as well as time to learn strategies for how to achieve educational goals from their mentors. 
Research Question 3: How do students understand the connection between choice of major and career aspirations?

Research question three asks how students understand the link between their choice of major and their career aspirations. A similarity between the two groups of students that emerged from my data was that many traditional and first-generation students linked their major to getting into and completing a graduate program. While several traditional students mentioned completing a graduate degree as a step towards realizing career goals, a striking finding of my research is that almost every first generation student planned to continue on to a graduate program as part of his or her career plan. Additionally, first generation students were more likely to link their major to specific occupational positions, while traditional students linked their majors to securing employment in a variety of positions in the same occupational area.

These findings suggest that first generation students have limited awareness of the available paths to a career. Traditional students, on the other hand, seem aware of more sophisticated strategies to achieve their career goals. My results build upon Ma's (2009) research that found that lower SES students tended to aspire to more secure majors with a strong likelihood of employment after graduation. Moving on to a graduate program and completing an advanced credential offers students perceived potential of a more secure path to a stable job. Having learned how to "be a successful student" as undergraduates, these college first-generation seniors may think that that a safer path to a desired occupation for them would be to earn another degree. First generation students are headed into uncharted occupational waters; they are not familiar with all that might be possible in a specific occupational area. Nevertheless, they do know that advanced 
degrees are more directly linked to specific occupations, such as social worker or pharmacist, than undergraduate degrees. Traditional students, on the other hand, are aware of multiple strategies to realized desired occupational goals. For example, Craig knows from his mother's experience that having a degree in sociology can qualify him for a job with local or state government. Lance has a father who has experience working with the government and the military. Lance knows that with his military experience and education there are multiple jobs available to him. Just like the first-generation students, traditional students get the benefit of going to college and acquiring skills associated with completing specific degrees. However, traditional students also receive benefits from their educated parents who have knowledge of and experience in occupational areas where desirable jobs are available to individuals with degrees but where those jobs are not necessarily limited to those with a specific degree.

Robst (2007) proposed that students who get degrees that encompass a more general skill set have more job opportunities than those that earn degrees that are very specific. With a few exceptions, traditional students are pursuing degrees that qualify them for multiple occupational positions. I argue that this strategy prepares these students to enter a very competitive work force. In comparison, first generation students are for the most part pursuing degrees that qualify them for specific or more constrained occupational options. According to Robst (2007) and Carnevale, Cheah, et al. (2012), these more specific types of jobs may offer better employment rates after graduation. However, if students are not able to find the specific job in their specialized skills qualified them for, they may have taken less desirable positions with lower wages (Robst 2007). 
In the next section, I will apply the theoretical lens of this study, Bourdieu's Theory of Social Reproduction and Cultural Capital $(1974,1984)$ to my findings. Bourdieu's theory helps to illustrate differences in the ways first generation and traditional community college transfer students choose their college majors, link their majors to desired careers, and the affect these choices have on their career outcomes. We also see whether completing college leads to social mobility or social reproduction.

Connecting findings to the theoretical framework

The most striking findings of this study are how differences in the effects of work, mentoring and family background influenced traditional and first generation community college transfer students' major choices, career choices and the ways they linked these two important choices in the pursuit of getting desired jobs. Each difference in the effect of specific factors on each groups' choices can be connected back to differences in social class, more specifically to students' respective levels of cultural and social capital with which they entered college. Traditional students came to college with an advantage, compared to first generation students, in terms of how knowledge of how to navigate the collegiate system, how to choose a major and how to link their major and course work to their career path. First generation students were able to gain some of this important cultural knowledge at college from mentors while at the college, but the differences in initial level of capital amounted to first generation students trying to compete in a race where traditional students were given a head start. 
My findings demonstrate how education-based SES intersects with students' major and career choices. In the following sections, I will apply Pierre Bourdieu's Theory of Social Reproduction and Capital. Specifically the concepts of habitus, social and cultural capital, and social space to my findings as I explore how differences in how traditional and first generation community college transfer students choose majors, make career choices, and connect majors to career choices, and how this may impact their chances for college success. Finally, I will bring all the pieces together and address the question of whether completing a college degree promotes social reproduction, social mobility, or both.

\section{Habitus}

Traditional students' habitus gives them an advantage over first generation students. How traditional students understand what is possible for them in society impacts how they choose their majors and plan to utilize their degrees to reach desired occupational positions. Traditional students' major and career choices were shaped by two sources: socializing agents and a changing society that forced them to adapt new strategies (Harker 1984). Traditional students' habitus, generated by out-of-college socializing agents such as parents and within-college agents such as professors and advisers, provided them with roadmaps for making their major and career choices. Traditional students came to higher education with a combination of habitus and capital that was conducive to college and career success. These students were able to build on their initial habitus and capital while at college. For example, Craig first became interested in the social sciences as a kid when he picked up and started reading through his mother's 
psychology textbooks. By the time Craig arrived at college he had read several social science books both from his home library as well as from his high school library. Additionally, Craig learned from his mother, who has a psychology and sociology degree that a degree in social sciences can lead to being hired for a variety of positions in local and state government. Lance, another traditional student, plans to use his political science degree to get a job working for the government in the security or law enforcement branches. His father has used his own degree to further his career in the military and has worked with the government in various capacities. Both Craig and Lance's parents provided them with knowledge that gives them much better ideas of which degrees are valuable for the careers each aspired to, and how one degree can qualify someone for multiple jobs in the same occupational area.

Not surprisingly, first generation students' habitus caused them to be anxious about their major and career choices. These students were sailing in uncharted waters. First generation students showed a lack of understanding of the collegiate system and the occupational fields they aspired to. More importantly, they lacked the knowledge to effectively align their major and class work to their occupational goals. They knew they aspired to particular careers but were confused about exactly how to structure their college paths in order to be positioned to claim the jobs they aspired to. This confusion comes from first generation students not having access to socializing agents within their family to assist them with major and career choices. First generation students needed to learn how to make choices using a different set of social rules than they grew up with; in addition, they had to discover resources that might effectively assist them in realizing 
their educational and career goals. For example, Jasmine shared that she was very confused by having to pick a career. She knew her parents could not assist her because they had not gone to college. Jasmine struggled to find a major that was a good fit for her and that could provide a number of job opportunities. To navigate these choices she needed the help of "socializing agents" that were not initially accessible to her within her family. Jasmine eventually received the information connecting majors with job opportunities from a mentor in a program for first generation students. The information Jasmine received from her college mentor was very similar to the information that traditional students Craig and Lance received from family members. While Jasmine received this needed information after she began college, Craig and Lance received this information prior to college while growing up in their families.

I argue that because of habitus, Craig and Lance took for granted the fact that they would succeed in college and get the jobs they aspired to. Because this view of what was possible for them developed at such an early age, they had time to make career plans and develop thoughts and ideas about how to realize those plans based on the knowledge their habitus provided. They had been mentally trying out ideas and strategies for realizing their goals over a long period and, as a result, had better ideas of what they realistically could and could not accomplish. Jasmine, on the other hand, had only recently been exposed to a view of what might be possible for someone like her - being able to attend college, earn a degree, and attain a high status career. While her habitus changed once she started college, Jasmine still had not had much time to work with this new knowledge and develop a sense of her place within the array of possible higher-SES occupations, afforded to her by earning a college degree. 
The combination of habitus and capital that traditional students began the university with provided them with foundational knowledge that they used to choose majors and careers that they were likely to realize. Traditional students were confident in their abilities to strategically follow a career path. This confidence was evident in the ways these students linked a single college major to multiple occupational positions. Habitus manifests itself in the form of personal dispositions. Traditional student were confident that earning a degree in their chosen college majors would enable them to attain the jobs they desired. First generation students, on the other hand, expressed anxiety about whether their major choices would earn them undergraduate degrees that would then help them earn their desired careers. It would be incorrect to assume that traditional students also were not anxious; however, they did not express this explicitly in their narratives. The confidence that these traditional students expressed is arguably the result of their habitus.

Once enrolled at college, first generation students benefited from the mentoring they received; they built upon their newly acquired cultural capital, and showed personal agency by undertaking actions they felt would help them succeed at college and pursue their occupational goals. However, the combination of habitus and capital they began college with did not provide first generation students with the same levels of confidence and beliefs in what might be possible for them to achieve that came naturally to traditional students. As first generation students completed more college courses, they acquired cultural capital and increased their beliefs about what they could accomplish. Mentors were overwhelmingly effective in helping first generation students build this new habitus. Traditional students came to the university with an expectation that they 
will succeed and that they had the right to expect professors, staff and administrators to assist them in realizing their goals. Traditional students' habitus also led them to believe that they could use their degrees to qualify for multiple jobs in a range of different occupational areas. The next section discusses the role that differences in levels of cultural and social capital played in these students' major and career choices.

\section{Cultural and Social Capital}

As noted in the previous subsection, besides possessing different habitus, traditional and first-generation community college transfer students began college with different initial levels of cultural and social capital. Moreover, as I explained in the earlier theoretical literature section, college is a time when all students accumulate additional cultural and social capital, regardless of what levels they begin school with. One way students acquire cultural capital is from their mentors. College-based professor and staff mentors provided both first generation and traditional students with useful information that influenced students' major and career choices. However, traditional students had the advantage of also receiving additional cultural and social capital about how to connect majors with desired occupations from their family and employer mentors. When family and employer mentors shared their own experiences of turning college degrees into desired occupations, they basically imported cultural capital to traditional students in the form of cultural knowledge that normally could only have been obtained by actual experience. 
First generation students in this study could not receive the same types of social and cultural capital from their family members or employers. The jobs that first generation students worked while attending school did not provide them with useable information that could help to guide them in their career path. First generation students also did not have access to family-based college knowledge. Most of the college knowledge these students possessed came to them from professor and adviser mentors after the students began college. For example, Monica, Anne and Bella, all firstgeneration students, expressed that mentors were a vital factor in their success. Specifically, each woman noted how a mentor provided her with cultural capital that assisted each of them in choosing her major and career, as well as showing the student how to link the two. Mentors' advice included how to create a class schedule, how to apply to graduate school, and insider information on the occupational field the students were aspiring to.

Traditional students gained their embodied cultural capital from their family mentors and employer mentors. The knowledge these students had about higher education and how to use a degree had become internalized, meaning it was second nature. To be clear, traditional students still needed to learn more about their major and its connection to possible jobs, but they came to the university with a strong foundation of knowledge to build on. For example, traditional students were able to link their majors to multiple occupational positions because their mentors made them aware that certain majors would qualify them for more than just one job. In contrast, first generation students were more likely to link their major to a specific occupation. These first generation students did not have prior work experience so they could see before starting 
college how specific college majors linked to specific jobs. They also could not rely on parents who could share experiences that could help to guide students' major choices and link specific majors to a career. First generation students gained knowledge of majors and careers after they came to college.

An important aspect of embodied cultural capital is internalizing cultural knowledge. First generation students did not have too much time to reflect upon and internalize the cultural capital they were gaining at college. They had to figure out how to use cultural and social capital while they were also being students. Traditional students, on the other hand, had acquired and internalized cultural knowledge about how choose majors and link them to career paths. Traditional students' parents and employers endowed them with this college and occupational appropriate cultural and social capital. For example, Maria shared that her father had several graduate degrees and this was a motivation for her to earn a graduate degree as well. Lance and Craig linked their knowledge of how to use their majors to knowing of their parent's experiences with their own major to career link. These are examples of embodied cultural capital and the powerful influence that having a parent or parents that have been successful in the work force with a degree can have. Within-college mentoring helped both groups of students to acquire cultural and social capital. However, traditional students came to college with a distinct advantage over first generation students. Their higher initial levels of capital allowed traditional students to maintain their relative advantage over first generation students even as both groups of students acquired additional social and cultural capital after they arrived at college. 
The previous two sections have looked at three elements of social class: cultural capital, social capital, and habitus. The following section will bring these concepts together and discuss the relationship of social class to students major and career choices.

\section{Social Space}

Traditional students come from a location in the social space that historically includes the field of higher education. Sharing the same social space, traditional students are more likely to be familiar with how a college degree can be used and what degrees match well with which occupational positions. For example, Hanna and Maria showed high levels of sophistication in the way they built upon their current work experiences to forward their own career goals. Their narratives suggest they were very comfortable with advocating for themselves and creating opportunities for advancement within their work places. Each of these women also had parents that worked in similar fields to the ones Hanna and Maria aspired to work in. It is logical to suggest that the both Hanna and Maria felt socially akin to the people at each of their current employers who worked at the jobs they aspired to hold themselves.

Ken is another example of a traditional student who feels very comfortable in his chosen field and the new positions that will open for him once he completes his degree. He asserted that he feels confident that he will get a job wherever he relocates to because of the combination of his military and civilian work background along with the degree he is working on. Hanna, Maria, and Ken all indicated that they were aware of several different occupational options available to each of them based on their respective degrees. This awareness demonstrates what Bourdieu (1984) explains as a privilege 
possessed by those that occupy more dominant positions in social space. Traditional students demonstrated an awareness of the link between specific degrees and particular occupational positions; this awareness reflects the advantages associated with their locations in social space.

First generation students beginning higher education are entering a field that is not associated with the social space they lived in for all of the rest of their lives. They are initially not clear about how to navigate this unfamiliar field. This unfamiliarity disadvantages them in several ways compared to traditional students. One result of this disadvantage is that first generation students do not have as full a comprehension of what can be done with their college degrees as their peers from families that are more educated. For example, Anne shared that she would not have thought about going onto graduate school had it not been for a mentor / academic adviser who explained options to pay for graduate school to her. Additionally, first generation students are not as familiar with which actions to take while they are in college to better their chances at getting a job after they graduate. For example, Liz's brother introduced her to someone at a company that was hiring an accounting intern. Neither Liz nor her brother knew that there are different kinds of internships and that sometimes what a company calls an internship is really just a low paying positions that does not really give any relative skill building opportunities. After being at the company for a few years, Liz realized that this internship was not in fact one that contributed to gaining the skills she needed to realize her occupational goals. First generation students do not have parents or personal experiences that can assist them in learning about the new location in the social space 
they are attempting to move into. This makes the processes of linking major choice to career realization much more difficult for first generation students.

The Big Picture

In this final sub-section, I would like to take a step backwards and look at the big picture about what is happening inside of higher education. Does completing a college degree promote social mobility or facilitate social reproduction? I propose both things are happening at the same time. Completing a college degree is providing social mobility for some students while simultaneously facilitating social reproduction for other students. In fact, social mobility for some college students can still be part of a larger process that reproduces the current stratified society. It works like this.

When first generation students complete college degrees, they now have opportunities for social mobility. For first generation students, the kinds of jobs they qualify for after completing their degrees have the possibility of moving them into a higher social class than that of their parents. While a few of their parents jobs required a two-year degree or certificate, first generation students who were earning four-year degrees aspired to occupational positions on a different social class-level from that of their parents. By completing their degrees, these students not only gained access to higher prestige occupations, they also expected financial rewards. College graduates, on average, accumulate higher yearly and lifetime earnings compared to individuals without degrees or those with two-year degrees.

At the same time, traditional students are earning degrees that help facilitate social reproduction. Traditional students take their degrees and obtain jobs that allow 
them to stay at the same social class level as their parents, both with regards to occupational prestige and earnings. It was common for traditional students to talk about aspiring to the same type of jobs as their parents in occupational areas such as engineering, project management, government work, and social work.

However, social mobility does not mean social equality. The payoffs that each group of students receives from completing their degrees are not equal. How can this be? Bourdieu would explain this by pointing out differences in each group's habitus and levels of cultural and social capital. The strategies and tactics needed to operate in a new or higher social economic status, are known to traditional students but unknown to first generation students. Yet having this knowledge is a very important part of making their degrees pay off as much as possible. One indicator of how these two groups of students intend to get their degree to payoff for them is how they link their major to their career. In my study, the ways in which first generation students made these links were safer or "tighter" than the riskier or "looser" strategies of traditional students. My findings suggest that traditional and first generation students possess different levels of college-towork expertise as the result of different levels of internalized familiarity with the occupations and majors that they were linking together.

Traditional students saw possibilities for themselves that allowed "looser" views of how to get their majors to pay off. These students knew that they could use their majors for a variety of jobs in different occupational areas. Traditional students did not feel a need to explicitly tie their major to a specific job. These students frequently mentioned that they felt confident that the combination of their work experience and their degree would get them a job. First generation students, on the other hand, held much 
"tighter" views of the actions needed to get their majors to pay off. First generation students saw limited possibilities for what they could do with their degrees. In this study, most first generation students were trying to tie their majors to specific occupational paths such as social worker or professor. In situations where first generation students tried to tie their majors to less specific occupational goals, they were unaware of how to proceed to achieve their occupational goals and spoke of them as far off dreams. Because no one in their families had earned a college degree, much less turned a college degree into a job, first generation students only learned from their college mentors about possibilities of turning their chosen majors into desirable careers. Regardless of their backgrounds, all of the students in this study increased their relative levels of cultural capital after they begin college.

While it is true that college students can build their own social connections starting from their first days on campus, it is not always clear to students who are the appropriate persons to connect with in order to realize specific goals. Bourdieu (1986) argues that social capital and cultural capital are created over time. It takes time to build quality relationships and to understand which individuals can provide the resources needed to succeed. This explains some of the trouble first generation students experienced after they started college. The knowledge they need to succeed was not present in their pre-college lives and could not be learned at a college orientation or in a brief meeting with an adviser. It takes both time and experience for students to recognize they lack this knowledge as well as to identify the people that might potentially be able to provide it to them. 
For many of the first students interviewed in this study, their experiences in negotiating university system seemed to influence their habitus. Mentors helped students learn ways to realize their dreams and goals, and, in the process, students' self-confidence increased. While these students continued to believe that hard work and determination played a very important part in their college success, they also realized that the assistance they received from mentors was invaluable. This is why mentoring programs are so important for first generation students who are having trouble adjusting to college. In this study, first generation students' conversations, even if they seemed short or casual, with advisers and professors had a lasting impact on the students' success.

Earning a college degree promotes social mobility for first generation students while also helping traditional students facilitate social reproduction. Therefore earning a college degree can simultaneously reproduce the social stratification and promote social mobility. First generation students who complete college degrees and obtain desired occupations increase their social class status. However, they are still at a disadvantage to traditional students. One reason for this is that both students came into the university with different levels of cultural and social capital. While they attended college, both groups of students increased their volume of capital. Yet it is very difficult for first generation students to gain enough capital to be on par with traditional students. No matter how much cultural and social capital mentors import to first generation students, these students are at a disadvantage because they did not begin college with the family based habitus and experience operating in the social class they are now aspiring to be members. 
The way in which social stratification factors impacted community college transfer students' major and career choices is another reason for this lack of social equality. Transfer students typically have two years at the university to finalize the construction of their career paths. Students need to be aware of the range of careerbuilding opportunities that are present at the university, and recognize which opportunities would best help them in attaining their desired jobs. First generation transfer students are at a disadvantage once they are at the university due to their limited knowledge about how choosing specific majors can facilitate or hinder realizing career goals. Their pre-university career path development has been limited due to an initial lack of family-based cultural and social capital. In many ways, first generation students are constructing their own road maps for getting through college and obtaining the occupations they aspire to. On the other hand, traditional students already knew the rules of the "college game." Even before they began college, traditional students benefited from having college-experienced people around them that could help them make the choices that would best help them achieve their goals.

Earning college degrees, moves first generation college students into a different social class than other first generation students who did not complete degrees. Earning college degrees also moves first generation students into the same social class as traditional students who do not complete college degrees but go into family businesses. That is the social mobility aspect of the effects of completing college degrees. The bigger question is, "does earning college degrees lessen the social class gap between first generation and traditional college graduates?" My findings suggest the answer to that question is, "Yes, but a gap still exists." 
Earning college degrees provides students with opportunities for social mobility and social reproduction, but does not necessarily equal the playing field for first generation students. Higher education is a vehicle for first generation students to improve their social class while still maintaining the privilege of the dominant class. This is the beauty of Bourdieu's explanation of how social reproduction is maintained in society. It does not require armed soldiers on every corner or tanks in the streets to maintain a stratified social system. For Bourdieu, micro-processes such as what a person thinks is possible impact macro structural issues such as who ends up with the most desirable positions in society. Individuals must be able to construct career paths in order to obtain desired occupations. My research draws attention to two important microprocesses, major and career choices, within higher education. Social class differences between traditional and first-generation community college students led them to link these two choices in different ways as part of constructing career paths that will result in differing societal level outcomes. And the irony is, because major and career choices are individual-level, freely chosen decisions, first generation students perceive any differences between their and traditional students occupational outcomes, as due to personal choices rather than structural factors.

This chapter connected the key findings to the literature and the theoretical framework used in this study. Additionally, this chapter presented the "big picture" story of how differences in the ways first generation and traditional community college transfer students choose college majors and link majors to desired careers affect career outcomes and whether completing college leads to social mobility or social reproduction. The next chapter will review the key findings and discuss the implications of this research for 
knowledge, practice, and theory. Additionally, this final chapter will present the limitations of this study and provide suggestions for future research. 


\section{CHAPTER SIX: CONCLUSION}

Introduction

In the final chapter, I will review the key findings of this study. I will then discuss the implications of the findings for knowledge, practice, and theory. Then I will review the limitations of this project. Lastly, I will discuss possible future research to build on this current study.

Key Findings

This study produced seven key findings; two related to major choice, two related to career choice, one in relation to mentor-provided advice, one related to the link between major and career choice, and one related to the micro-processes of major and career choice in higher education. The following subsections will review each of these key findings.

Major Choice

My first key finding is that college-based mentoring affected first generation community college transfer students' major choices but not those of traditional community college transfer students. Mentoring influenced first generation students' major choices in two ways. First, professor and adviser mentors helped students create class schedules that allowed them to complete the course sequences needed to achieve their degrees.

Secondly, mentors validated first generation students' intentions to get their degrees; this validation helped these students believe in their abilities to do the necessary course work. 
In comparison, traditional students did not report that college-based mentors influenced their major choices

My second key finding is that work experience influenced traditional student's major choices but not those of first generation students. First generation students mentioned that for them, work was primarily for "paying the bills".

\section{Career Choice}

The third key finding from my study was that work experience influenced both groups' career choices differently. Traditional students used their past and current work history to assist them in strengthening their chances at realizing their career goals. Many traditional students planned to use the degrees they earned at college to advance within fields they already were working in. In comparison, it was only after they started college and settled on specific majors that first generation students looked for work experiences to help explore possible occupational outcomes. This finding, combined with the previous one, suggests that traditional students come to college with work experiences that helps them make major and career decisions that strengthen their chances of realizing their career goals. Conversely, first generation students must find assistance with making the same choices after they arrive to college.

My fourth key finding is that while mentoring influenced both groups of students' career choices; there was a difference in who provided the mentoring. Academic advisers and / or professors mentored both traditional and first-generation community college transfer students about how to realize their career goals. However, traditional students received additional mentoring from family and employer-mentors. 
Mentor-provided advice

The fifth key finding of my study was that there was a difference in the kind of mentorprovided information each group of students received. College mentors gave both groups of student's domain-specific information regarding their careers, such as what jobs a student can qualify for with a degree in sociology. In addition, traditional students got "life advice" from family mentors about how they themselves had connected degrees and careers. This additional information provided traditional students with valuable cultural capital that first generation students did not have access to in their own families.

\section{Major to Career Link}

My sixth key finding is that the two groups of students differed in the ways in which they linked their chosen majors to possible careers. Traditional students understood their majors as giving them access to multiple jobs in a given occupational area while first generation students linked their majors to achieving specific occupational positions. This finding speaks to the different "understandings of what are possible in the world" that each group of students used to link their major to a career. Traditional students exhibited a feeling of confidence that the combination of their degree and their past work experience would qualify them for a number of jobs in an occupational area. Their strategy could be considered "loose" or risky. On the other hand, first generation students, by linking their major to a specific job or career, were undertaking what I am labeling as a "tighter" or safer strategy. Traditional students, for the most part, believed they could use their degrees in a fluid manner to realize their career goals. They 
recognized their degrees could qualify them to jobs in areas that were not explicitly tied to the major of their college degrees.

Micro-processes of major and career choices

The final key finding is the outcome of synthesizing the previous findings. This synthesis suggests that earning college degrees simultaneously promote social mobility for some students while facilitating social reproduction for others. Even when earning college degrees promotes social mobility for some students, this happens within a process of social reproduction. I suggest that the micro-processes of major and career choice are ways that higher education reproduces a stratified social system. I will elaborate on this finding in more detail in the section on "implications for theory."

The next section will discuss the implication of this study for knowledge, practice, and theory.

Discussion of Implications

These findings add to knowledge by outlining the micro processes traditional students used to link their major and career choice. Additionally, these findings have implications on practice by illustrating that that mentoring programs as well as informal and formal mentors can assist students to better understand how to choose a major and career as well as how to link the two. Finally, this research adds to theory by exploring how the micro process of major and career choice act to perpetuate macro structural issues of who gets the best jobs in society. 
Knowledge

The findings of my research have implications for the construction of new knowledge about how traditional and first generation community college transfer students use different strategies to choose their majors, career paths and link the two. In this study, I have shown that traditional community college transfer students come to college with inherited cultural capital and resources that give them an advantage in choosing a major and linking it to a career. The two primary resources of this capital come from traditional students' work experiences and mentors that they had established prior to college. Work experiences and mentors could be viewed as neutral experiences that are available to everyone. The first generation students in my study certainly had work experiences and were also mentored after they started college. However, my findings suggest that traditional community college transfers students were able to take advantage of their work experiences as well as the cultural capital transferred to them from family and employer mentors to continue their class advantage.

One of the most important outcomes of access to these resources is how they helped traditional students link their major to multiple job opportunities and have confidence in their ability to succeed in their occupational field. By having confidence in their ability to use their experience and their degree, these traditional students have a "looser" view of what is possible for them. They recognize possible employment opportunities that might not be obvious to first generation students. The strategies of traditional students would be considered risky by most first generation students, who do 
not possess the same cultural capital and are limited in their view of what is possible to them in the workforce.

Even though, since they enrolled in college, first generation students have increased their relative levels of cultural capital and have expanded their views of what they might be able to accomplish in life, they are still not able to catch up with traditional students. These first generation community college transfer students come into college having to "learn the ropes" as they go. The findings in my study suggest that, once they are in college, these students become aware of ways to use a degree to qualify for valued positions in the work force. However, first generation students have a "tighter" or safer view of their options. This is illustrated by the fact that every first generation student but one planned to go to graduate school to qualify for a specific occupational position. These students were all using the strategy that earning additional credentials would increase their chances of landing desired careers. The one student who did not plan to go to graduate school planned instead to take a state board to become a licensed certified public accountant, another very specific occupational position. The difference between the two groups of students was very apparent in where their knowledge came from with regards to major and career choices. For these first generation students, college-based mentors were their only real source of cultural capital students could use to make major and career choices in order to achieve their educational and occupational goals. 
Practice

The findings of my research also have implications for practice with regards to how students, and particularly community college transfer students, are mentored at college. In order to understand the barriers that first generations community college students encounter when trying to make effective major and career choices at the university it would be helpful for college mentors to be aware of these students' relative deficits in cultural capital, as well as the mechanism by which cultural capital is transferred to students. Transfer students have a limited time at the university, and it is assumed that when they transfer they have already developed the appropriate foundations for making informed major and career choices while at their community colleges.

Based on my findings, the professor and adviser mentors at PSU are providing all students with useable domain specific information about which jobs might be possible for students who graduate with specific degrees. However, first generation community college students are not starting out at the university with the same kind of foundations for making major and career choices that traditional students have. Differences in habitus and family-based cultural capital put first generation students at a disadvantage.

Within higher education, student success programs give first generation students boosts in cultural capital, and help them make better decisions. One way to help first generation students make more strategic choices is by strengthening these programs with more mentors, staff, and support from universities and community colleges. The process of the accumulation of cultural capital does not happen overnight. It takes both time and personal investment to build cultural capital. Several of the students in this study were 
members of groups that served first generation and low income students. However, not all the first generation students who qualify for these groups know that such groups exist. Something that can be done right away is to encourage professors, academic advisers, and the groups themselves to promote on-campus awareness of these student success groups.

Once students transfer to the university mentoring programs that match first generation students to mentors/alumni in their occupational fields of interest would be another way to help them make informed major and career choices. First generation students in my study often commented that they needed help connecting choices, such as setting up course schedules or choosing majors, to their overall occupational goals. These students lack a useable road map to help them get from where they are after transferring to the university to reaching their desired careers. For example, there are certain positions in a firm that can increase one's chances at being promoted to management positions, while others do not. There are certificates that can help one be advanced faster, while other certificates will not help. Each occupation has insider information and cultural knowledge that if known, improves one chances. Traditional students may have this information because of cultural capital passed down from their parents. If they do not receive appropriate mentoring after transferring to the university, first generation students will find themselves in a similar situation to when they first started college; full of desire and the will to work hard but a lack of knowledge to effectively and efficiently choose actions that link to their success. 
Theory

Finally, the findings of my research have implications for theory, specifically Bourdieu's Theory of Social Reproduction and Capital. My findings show that micro-processes related to major and career choices and the links traditional students make, reinforce how the macro structural issues of who gets the best jobs in a society happen. Bourdieu's original research looked at how class-based differences in language usage by French elementary school students led their teachers to evaluate the performance of children from more educated families more favorably than the performance of students from working class families. Bourdieu went on to show that not only did the teachers' think the upper class students' performance was due to superior academic abilities rather than just using familiar styles of language, but that the favorable teacher evaluations benefited upper class children for the rest of the academic careers as they were placed on higher academic tracks.

While there has been a large amount of research in the United States using Bourdieu's theory to examine how micro processes of language and teacher's expectations are utilized to maintain social stratification in K-12 education, there has been little research done on the micro processes that occur in college that lead to the reproduction of social class. My study has shown that the family background-based advantages that lead to differences in students' K-12 success actually continue after they enter higher education. Therefore, the story of these first generation and traditional students does not start with the transition from community college to the university that is the focus of this study. Instead, it starts early on in their educational lives. 
The micro-processes in K-12 link to those of college like this. Students from families with a higher-education based SES learn how to use language and develop a disposition that identifies them as "good students" in the eyes of school authorities(Bourdieu 1993; Lareau and Horvat 1999). As a result of cultural capital, traditional students are put into academic tracks that increase their advantage. This is done by giving them access to, and attention from, teachers and thereby the knowledge needed to succeed at a high level (Lareau 2011). Additionally, these interactions with teachers gives them confidence in working with authorities. Furthermore, through participating in activities that have the highest cultural reward such as going to museums, math camps or extracurricular activities attached to learning these students gain acceptance by teachers and peers (Lareau and Weininger 2003). These students' success in K-12 education carried over into college. All of the students in my study began their post-secondary careers at community colleges. I picked up their stories after they transferred to the university.

I propose that within higher education, an important micro process is decision making. Once a student enrolls in college, and particularly once a student transfers from a community college to the university, major and career choices as well as knowing how to choose a major and link it to a career path in a way that maximizes degrees effectiveness become very important. Major and career choice appear to be based on free will, but traditional students operate with prior cultural capital derived from their habitus that allows them to link their choices of major to carrier options that have the best pay out. Similar to learning how to talk to and be accepted by school authorities in primary school, once in college traditional college students can use this knowledge to navigate 
the colligate system and take advantage of mentors that in turn allows them to get the most out of their degrees.

Additionally, these traditional students know how to move from being a "good student" to that of being a "good employee." Here again their career choices and strategies for realizing career goals appear to be based on free will or hard work. Their knowledge of what types of jobs to apply to and how to connect that job to their major choice and that major to future employment opportunities is really the product of years of socialization.

Let us step back and look at the life trajectory of these traditional students. Traditional students received imported cultural capital from their parents; the transmission of this capital started when they were young. Traditional students learned from their parents that earning college degrees was essential to getting good jobs like the ones their parents currently had. Their parents shared cultural capital in the form of stories about their college experiences, and how they ended up with the careers they did. Traditional students have had years to become aquatinted with this capital and learn how to use it. While in high school and then in college, they have built on that capital, and continued to increase their knowledge of how to take advantage of opportunities in society. The career outcomes for traditional students are a reinforcement of their advantage as well as a reproduction of the social structure. This is accomplished through micro processes of major and career choice that in turn have effects on macro structural outcomes such as obtaining the best jobs. Traditional students metaphorically, are running a race for the best jobs and are getting to start in the middle of the race. 
First generation students, on the other hand, are running in the same race but they are starting out far behind their traditional student peers. Their success depends on knowing the same knowledge and strategies that traditional students use but the first generation students struggle to make up the time they have lost. Major and career choice for these students may appear to be based on "free will" but the resources they have to help them make these choices are severely limited in both volume and composition in comparison to the variety of resources traditional community college transfer students have. By drawing attention to the importance of how family-background impacts major and career choices for community college transfer students after they arrive at the university, my research contributes to Bourdieu's explanation of how education at all levels contributes to the reproduction of a socially stratified society.

\section{Limitations}

There are several possible limitations associated with this research that must be considered. These are in the areas of, sample size, recruitment, use of demographic information, data collection, and methods of analysis.

The first limitation relates to sample size. Due to the small sample size, even though a large amount of data was gathered from this sample, the results of this study are not generalizable. They are transferable to a similar population of students in a similar setting.

The second limitation is in the area of recruitment. Two main areas comprise this limitation, the method of selection, and the criteria for participation. The students for this study were purposively recruited by word of mouth and snowball procedures. Although a 
set of strict criteria via a screening survey was used to, select participants there are still the possibility for selection bias. On reason for potential selection bias is that students needed to respond to the call for participants, access an on-line screening survey, spend 5-8 minutes filling out the survey, respond to a follow up email informing them that they had been selected, and lastly, schedule and participate in their interview. The amount of initiative and time needed to participate may have limited the participation of some students.

Another limitation in regards to recruitment is the role that student success groups, that served first generation students, played in disseminating the initial call for participants. One results of this approach was that a large number of first generation students who were in these programs decided to participate in my study. Student members of these groups get mentoring and advice that other first generation students do not get. The few first-generation students in the study that were not in a program may have used different strategies to choose their major and career. However, there were not enough participants to compare responses of students from success program with first generation students who were not in those kinds of programs.

In regards to selection, students were selected to participate in my study without regard as to what their majors were. It is possible that there could be a similarity of stories within a certain department or college within PSU. For example, academic advising is often done differently from department to department. Some disciplines require frequent interaction with an academic adviser and some do not. These differences in advising/mentoring might impact how students made major and career choices, as well as the level of information they had about connecting majors to desired careers. 
Additionally, this research did not account for race, age, or gender. It is possible that anyone of these factors or a combination of these factors could play a role in major and career choices, work experience or the types of mentors available to students.

The method of data collection, I used a semi-structured interview guide along with a conversational interviewing style, could also be a limitation. Due to the nature of this method of data collection, participants might have felt they should tell me what they thought I wanted to hear. Another possible limitation is the way the analysis was conducted for this project. While I tried to keep the voices of the students intact, the mere use of thematic analysis can cause some of the student's voice to be lost due to cutting up the narrative.

Future research

The act of conducting this thesis project has given me several insights into possible directions for future research. There continues to be a discussion in the educational literature about whether earning a college degree promotes social mobility or contributes to social reproduction. Particularly in light of the current high rates of unemployment in the United States, the social mobility-social reproduction argument cannot stop with whether students complete college degrees; it must include how students are connecting chosen college majors to actual jobs. My study utilized a comparative interview design to explore the lived experiences regarding major and career aspirations of first-generation and traditional college seniors who have transferred from a community college to a state university. The results of this study suggest that community college transfer students' 
family backgrounds impact the major and career choices they make after they transfer, as well as the paths they follow in trying to turn their chosen degrees into desired careers.

In a future project, I would like to design and undertake a more comprehensive study that builds upon the findings of this research in order to try to understand the effectiveness of students' career choice strategies and occupational outcomes. Using a larger sample size with participants from more than one college and utilizing a mixed methods approach, future sociological treatments of this research topic could shed more light on the micro-processes used by students as well as occupational outcomes. One approach would be to conduct a longitudinal study that would have two parts. In the first part one-on-one interviews would be used to follow community college transfer students who are seniors at a state university through two years past graduation. The data from this qualitative phase would supplement the creation of a survey instrument that could be used to collect data from a larger participant pool and develop generalizable results. Specifically, to explore how students understand their transition from the university to an occupational location and what factors have the strongest relationship with their occupational placement. This design would be able to collect data on how choices are being made while in college as well as how students are making choices after college. While the current research looked at parental education as a measure of social class, future research designs could include additional class indicators such as parents' occupations to help explore the effects of different aspects of parents' social class on students' major choices and occupational outcomes. This will begin to move this line of research into a realm of being able to be generalizable and help policy makers in a variety 
of community colleges, state colleges, and universities help first generation and lowincome students succeed in their chosen occupational field.

Another potentially fruitful line of future research might be to identify and explore other micro-processes within higher education that contribute to differential student outcomes. In addition, research that could shed light upon how individuals' class backgrounds impact other, freely chosen but high-stakes decisions, would provide a further test of the applicability of Bourdieu's Theory of Social Reproduction to higher education.

Recession, globalization, and job in-security are salient subjects for many people in the United States. In response to these social problems, many people are using higher education to increase their chances of successfully finding stable employment. Many of these students go through the community college and transfer to a university to finish their four-year degree. The large flow of people using the community college in this way has resulted in an increase of research regarding students that transfer from a community college to a university to finish their four-year degree. While there has been a considerable amount of research on issues of persistence and the transition between the community college and the four-year university there has been little research on the occupational outcomes of these students. This study has drawn attention to how microprocesses of major and career choice within higher education result in students earning degrees that simultaneously promote social mobility and facilitate social reproduction. In today's competitive economy, all community college transfer students need support making informed major and career decisions after the arrive at the university. In order to lessen the gap between the haves and have not's it is vital for college-based mentors to 
help first generation students make the most of their opportunities after they transfer to the university by providing these students with the cultural capital they cannot access at home. I hope that my research helps draws attention to the importance of major and career choices on students' occupational outcomes and can lead to better opportunities for all students. 


\section{References}

Arcidiacono, Peter. 2004. "Ability Sorting and the Returns to College Major." Journal of Econometrics 121(1-2):343-75.

Aries, Elizabeth, and Maynard Seider. 2007. "The Role of Social Class in the Formation of Identity: A Study of Public and Elite Private College Students." Journal of Social Psychology 147(2):137-58.

Bamball, Louise, and Alison While. 1994. "Collecting Data Using a Semi-structured Interview: a Discussion Paper.” Journal of Advanced Nursing (19):328-35.

Bourdieu, Pierre. 1974. "Cultural Reproduction and Social Reproduction.” Pp. 71-112 in Knowledge, education, and cultural change: Papers in the sociology of education., edited by Richard K. Brown. London: Tavistock.

Bourdieu, Pierre. 1984. Distinction A Social Critique of the Judgment of Taste. Harvard University Press.

Bourdieu, Pierre. 1986. "The Forms of Capital.” Pp. 241-58 in Handbook of Theory and Research for the Sociology of Education. New York: Greenwood.

Bourdieu, Pierre. 1989. "Social Space and Symbolic Power.” Sociological Theory 7(1):14-25.

Bourdieu, Pierre. 1993. The Field of Cultural Production, Essays on Art and Literature. Columbia University.

Byrd, Kathleen L. MacDonald. 2005. "Defining College Readiness from the Inside Out: First-Generation College Student Perspectives." Community College Review 33(1):22-37.

Carnevale, Anthony P., Ban Cheah, and Jeff Strohl. 2012. Hard Times. College Majors, Unemployment and Earnings. Not All Degrees Are Created Equal. Georgetown University Center on Education and the Work Force. Retrieved April 24, 2012 (http://cew.georgetown.edu/unemployment/).

Carnevale, Anthony P., Tamara Jayasundera, and Ban Cheah. 2012. The College Advantage: Weathering the Economic Storm. Executive Summary. Georgetown University Center on Education and the Work Force. Retrieved (http://www9.georgetown.edu/grad/gppi/hpi/cew/pdfs/CollegeAdvantage.Executi veSummary.081412.pdf). 
Cebula, Richard J., and Jerry Lopes. 1982. "Determinants of Student Choice of Undergraduate Major Field." American Educational Research Journal 19(2):30312.

Collier, Peter J., and David L. Morgan. 2008. “'Is That Paper Really Due Today?': Differences in First-Generation and Traditional College Students' Understandings of Faculty Expectations." Higher Education 55(4):425-46.

Crisp, Gloria, and Irene Cruz. 2009. "Mentoring College Students: A Critical Review of the Literature Between 1990 and 2007." Research in Higher Education 50(6):525-45.

Erkut, Sumru, and Janice R. Mokros. 1984. "Professors as Models and Mentors for College Students.” American Educational Research Journal 21(2):399-417.

Gibbons, Melinda M., and Marie F. Shoffner. 2004. "Prospective First-Generation College Students: Meeting Their Needs Through Social Cognitive Career Theory." Professional School Counseling 8(1):91-97.

Grimes, Sue K. David. 1999. "Underprepared Community College Students: Implications of Attitudinal and Experiential Differences." Community College Review 27(2):73.

Harker, Richard K. 1984. "On Reproduction, Habitus and Education." British Journal of Sociology of Education 5(2):117-27.

Horvat, Erin McNamara, Elliot B. Weininger, and Annette Lareau. 2003. "From Social Ties to Social Capital: Class Differences in the Relations Between Schools and Parent Networks." American Educational Research Journal 40(2):319-51.

Inman, Elliot W., and Larry Mayes. 1999. "The Importance of Being First: Unique Characteristics of First Generation Community College Students." Community College Review 26(4):3.

Johnson, Monica Kirkpatrick, and Jeylan T. Mortimer. 2011. "Origins and Outcomes of Judgments About Work.” Social Forces 89(4):1239-60.

Kane, Thomas J., and Cecilia Rouse. 1999. "The Community College: Educating Students at the Margin Between College and Work." The Journal of Economic Perspectives 13(1):63-84.

Laden, Berta Vigil. 2000. "The Puente Project: Socializing and Mentoring Latino Community College Students." Academic Exchange Quarterly, 90.

Lareau, Annette. 2003. Unequal Childhoods. Berkely and Los Angeles, California: University of California Press. 
Lareau, Annette. 2011. Unequal Childhoods, Class, Race, and Family Life. Second Edition. Berkley and Los Angeles, California: University of California Press.

Lareau, Annette, and Erin McNamara Horvat. 1999. "Moments of Social Inclusion and Exclusion Race, Class, and Cultural Capital in Family-School Relationships." Sociology of Education 72(1):37-53.

Lareau, Annette, and Elliot B. Weininger. 2003. "Cultural Capital in Educational Research: A Critical Assessment." Theory and Society 32(5/6):567-606.

Leppel, Karen, Mary Williams, and Charles Waldauer. 2001. "The Impact of Parental Occupation and Socioeconomic Status on Choice of College Major." Journal of Family and Economic Issues 22(4):373-94.

London, Howard B. 1989. "Breaking Away: A Study of First-Generation College Students and Their Families.” American Journal of Education 97(2):144-70.

Luttrel, Wendy. 1996. "Becoming Somebody in and Against School: Toward a Psychocultural Theory of Gender and Self Making." Pp. 93-118 in The Cultural Production of the Educated Person, edited by Bradley Levinson, Douglas Foley, and Dorothy Holland. Albany, New York: State University of New York.

Ma, Yingyi. 2009. "Family Socioeconomic Status, Parental Involvement, and College Major Choices - Gender, Race/Ethnic, and Nativity Patterns.” Sociological Perspectives 52(2):211-34.

Marshall, Catherine, and Gretchen Rossman. 2011. Designing Qualitative Research. 5th ed. SAGE Publications.

Montgomery, Laura. 2004. “'It's Just What I Like': Explaining Persistent Patterns of Gender Stratification in the Life Choices of College Students." International Journal of Qualitative Studies in Education (QSE) 17(6):785-802.

Montmarquette, Claude, Kathy Cannings, and Sophie Mahseredjian. 2002. "How Do Young People Choose College Majors?" Economics of Education Review 21(6):543-56.

Pascarella, Ernest T., Christopher T. Pierson, Gregory C. Wolniak, and Patrick T. Terenzini. 2004. "First-Generation College Students: Additional Evidence on College Experiences and Outcomes." The Journal of Higher Education 75(3):249-84.

Patton, Michael. 1980. Qualitative Evaluation Methods. SAGE Publications.

Perin, Dolores. 2006. "Can Community Colleges Protect Both Access and Standards? The Problem of Remediation." Teachers College Record 108(3):339-73. 
PSU. 2012a. "Enrollment Management \& Student Affairs: Advising." Enrollment Management \& Student Affairs: Advising. Retrieved March 6, 2012 (http://pdx.edu/advising/class-standing).

PSU. 2012b. "PSU Transfer Admission." Portland State University, Enrollment Management \& Student Affairs: Admissions. Retrieved March 6, 2012 (http://pdx.edu/admissions/transfer-admission).

PSU. 2012c. "Transfer Student Services." Transfer Student Services, Portland State University. Retrieved April 24, 2012 (http://pdx.edu/transferstudent/).

Reay, D. 2004. “'It's All Becoming a Habitus': Beyond the Habitual Use of Habitus in Educational Research." British Journal of Sociology of Education 25(4):431-44.

Reid, M. Jeanne, and James L. Moore. 2008. "College Readiness and Academic Preparation for Postsecondary Education." Urban Education 43(2):240 -261.

Robst, John. 2007. "Education and Job Match: The Relationship of College Major and Work." Economics of Education Review 26:397-407.

Swartz, David. 1997. Culture and Power, The Sociology of Pierre Bourdieu. Chicago: University of Chicago Press.

Terenzini, Patrick T. et al. 1994. "The Transition to College: Diverse Students, Diverse Stories." Research in Higher Education 35(1):57-73.

Terenzini, Patrick T., Leonard Springer, Patricia M. Yaeger, Ernest T. Pascarella, and Amaury Nora. 1996. "First-Generation College Students: Characteristics, Experiences, and Cognitive Development." Research in Higher Education 37(1):1-22.

Townsend, Barbara K., and Kristen Wilson. 2006. “'A Hand Hold for A Little Bit': Factors Facilitation the Success f Community College Transfer Students to a Large Research University.” Journal of College Student Development. 47(4):43956.

Tyson, Karolyn. 2011. Integration Interrupted, Tracking, Black Students, and Acting White after Brown. Oxford University Press.

Weininger, Elliot. 2005. "Foundations of Pierre Bourdieu's." Pp. 82-118 in The Approaches to Class Analysis, edited by Erik Wright. Cambridge University Press. 


\section{Appendix Interview Guide}

What is your current Major?

How many majors have you had since you started college?

Probe

- What was your first major at the CC?

Probe: Why did you choose this major? Who or what experiences influenced this choice?

What kind of career opportunities do you think there are for someone with this major?

- If you changed your major while at the $\mathrm{CC}$, tell me about that experience.

- What was your major when you transferred to PSU?

Probe: Why did you select this major before starting at PSU? Who or what experiences influenced this choice? What kind of career opportunities do you think there are for someone with this major?

- If you changed your major since transferring to PSU, tell me about that experience. Probe: Who or what experiences influenced this choice? What kind of career opportunities do you think there are for someone with this major?

Tell about when you first starting thinking about your current major?

Let the person talk. If they do not discuss it then ask them how they feel about their major now and then how they felt about their major at the community college and again after, they entered PSU. As a note, previous research has often considered major and career as one in the same in an interview. Participants may do the same thing. If they do, probing questions will be used to separate the two out.

What do you believe are the benefits of your current major?

- How does this major relate to your career goals?

- What are some of the benefits of X major?

- Probe: what specific jobs would you be able to do if you graduate with a Bachelor's degree in this major?

What is your ultimate career goal?

Immediately after you complete your bachelor's degree at PSU, what is the first step towards realizing your ultimate career goal?

Tell me about who the biggest influences for you in regards to your major are. 
This question may get answers that indicate particular people as well as experiences and events in their lives. Each area will be picked up and probed for more details as it relates to any choice of major or shift in major that was discussed earlier.

"I am interested in whom certain people may have influenced you. One of those types is that of a Mentor. By that, I mean a person that may have taken an interest in you and has offered you support and advice to help you with your academic and professional goals and development.

Mentors can be formally set up or informally arranged."

Can you identify any mentors you have had while being in college?

For each person mentioned ask:

How has influenced your choice of major and career aspirations?

Probe for the time when this person was influential and if the student has changed majors over their college career make sure to cover each transition. The goal of this line of questioning is to see whom if anyone was influential in each shift of major choice.

Probe for each person mentioned that was not identified as a mentor and apply the same question and probing technique.

If influences other than people come, up such as a class, an ad, a lecture or event probe for when each occurred and what major shift it related to.

Tell me about who were the biggest influences for you in regards to your career goals.

This question will be addressed exactly like the pervious question.

Tell me about the paid work you do / have done during the time you have been attending college.

Probe: how does this work connect with realizing your career goals?

How does your college major relate to the paid work you do/have done during the time you have been attending college

Knowing what you know now what, would you have done differently in choosing your major when you began at the CC?

Knowing what you know now what, would you have done differently in choosing your major when you transferred to PSU? 
Knowing what you know now what, would you have done differently in choosing your current major?

Knowing what you know now, what would you have done differently in choosing the paid work you did during the time you were attending college?

Knowing what you know now what, would you have done differently in regards to identifying and connecting with useful mentors who could advise you on major and career choices?

Probelemphasize particularly during the time you were attending college.

(If there is time) Knowing what you know now what, would you have done differently in choosing your career?

Is there anything else you would like to share with me that we have not covered, regarding your major and career choices? 